\title{
Epithelial argininosuccinate synthetase is dispensable for intestinal regeneration and tumorigenesis
}

Jonathan H. M. van der Meer ${ }^{1}$, Ruben J. de Boer ${ }^{1}$, Bartolomeus J. Meijer (iD ${ }^{1}$, Wouter L. Smit ${ }^{1}$, Jacqueline L. M. Vermeulen ${ }^{1}$, Sander Meisner (iD ${ }^{1}$, Manon van Roest (iD ${ }^{1}$, Pim J. Koelink ${ }^{1}$, Evelien Dekker ${ }^{2}$, Theodorus B. M. Hakvoort ${ }^{1}$, Jan Koster (iD ${ }^{3}$, Lukas J. A. C. Hawinkels (iD ${ }^{4}$, Jarom Heijmans ${ }^{1}$, Eduard A. Struijs ${ }^{5}$, Marja A. Boermeester ${ }^{6}$, Gijs R. van den Brink ${ }^{1,7}$ and Vanesa Muncan (iD) ${ }^{1 凶}$

(c) The Author(s) 2021

The epithelial signaling pathways involved in damage and regeneration, and neoplastic transformation are known to be similar. We noted upregulation of argininosuccinate synthetase (ASS1) in hyperproliferative intestinal epithelium. Since ASS1 leads to de novo synthesis of arginine, an important amino acid for the growth of intestinal epithelial cells, its upregulation can contribute to epithelial proliferation necessary to be sustained during oncogenic transformation and regeneration. Here we investigated the function of ASS1 in the gut epithelium during tissue regeneration and tumorigenesis, using intestinal epithelial conditional Ass 1 knockout mice and organoids, and tissue specimens from colorectal cancer patients. We demonstrate that ASS1 is strongly expressed in the regenerating and Apc-mutated intestinal epithelium. Furthermore, we observe an arrest in amino acid flux of the urea cycle, which leads to an accumulation of intracellular arginine. However, loss of epithelial Ass 1 does not lead to a reduction in proliferation or increase in apoptosis in vivo, also in mice fed an arginine-free diet. Epithelial loss of Ass 1 seems to be compensated by altered arginine metabolism in other cell types and the liver.

Cell Death and Disease (2021)12:897; https://doi.org/10.1038/s41419-021-04173-x

\section{INTRODUCTION}

Epithelial tissues in healthy adult organs, such as the intestinal epithelium, are in a state of homeostasis, where the rates of cell division and cell death are in a dynamic equilibrium. Loss of epithelial cells by damage is rapidly compensated for by increased proliferation until the number of differentiated cells is restored and proliferation is reduced to homeostatic levels [1, 2]. This repair process is driven by repopulation of the stem cell pool by surviving stem cells, dedifferentiation of more committed progenitor cells that are able to adopt a stem cell phenotype and hyperproliferation [3, 4]. Multiple parallels can be observed between the process of epithelial repair and oncogenesis, which largely involves the same mechanisms and pathways, with the notable exception that homeostasis is not restored due to the presence of somatic mutations that disrupt the possibility of negative feedback regulation $[5,6]$.

To provide the cell with its requirements for accelerated growth under challenging conditions, cellular metabolism is grossly altered [7]. For instance, cancer cells often rely on glycolysis instead of oxidative phosphorylation, a phenomenon known as the Warburg effect [8]. In some types of cancer, certain nonessential amino acids may become essential, such as leucine, serine, and arginine [9, 10], while in other types of cancer an increase in the synthesis of amino acids can be observed [11-13]. Because of the similarity between the mechanisms involved in regeneration and oncogenesis, understanding these metabolic changes in cancer could not only provide therapeutic targets for cancer, it may also unveil treatment options for other diseases, like inflammatory bowel disease and several autoimmune disorders, which are characterized by impairment of the regeneration process and intestinal barrier function [14-16].

The amino acid arginine is a direct substrate for protein synthesis, as well as a precursor for nitric oxide, urea, creatine, polyamines, agmatine, proline, and glutamate [17]. Arginine is a conditionally essential amino acid, meaning that availability of arginine becomes critical, mainly during the processes of growth and repair. As mother's milk contains too little arginine to sustain the rapidly growing embryo and neonate, arginine is synthesized from proline and glutamine that are abundantly present in that milk. The rate-limiting enzyme for this synthesis is argininosuccinate synthetase 1 (ASS1). ASS1 catalyzes a key intermediate step in which citrulline and aspartate are converted to argininosuccinate. Argininosuccinate lyase (ASL) subsequently converts

\footnotetext{
'Amsterdam UMC, University of Amsterdam, Tytgat Institute for Liver and Intestinal Research, Amsterdam Gastroenterology Endocrinology Metabolism, Meibergdreef 69-71, Amsterdam, The Netherlands. ${ }^{2}$ Amsterdam UMC, University of Amsterdam, Department of Gastroenterology and Hepatology, Amsterdam Gastroenterology Endocrinology Metabolism, Meibergdreef 69-71, Amsterdam, The Netherlands. ${ }^{3}$ Amsterdam UMC, University of Amsterdam, Department of Oncogenomics, Cancer Center Amsterdam, Meibergdreef 9, Amsterdam, The Netherlands. ${ }^{4}$ Department of Gastroenterology and Hepatology, Leiden University Medical Center, Leiden, The Netherlands. ${ }^{5}$ Amsterdam UMC, Vrije Universiteit Amsterdam, Department of Clinical Chemistry, Amsterdam Gastroenterology Endocrinology Metabolism, de Boelelaan 1117, Amsterdam, The Netherlands.

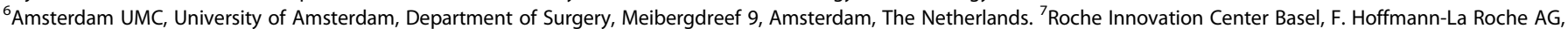
Basel, Switzerland. ${ }^{凶}$ email: v.muncan@amsterdamumc.nl

Edited by Dr Cristina Munoz-Pinedo
}

Received: 7 May 2021 Revised: 23 August 2021 Accepted: 9 September 2021

Published online: 01 October 2021 
argininosuccinate into arginine and fumarate. As a result, ASS1 is highly expressed by the enterocytes of the small intestine during prenatal and neonatal development. Expression of ASS1 is lost during the suckling-to-weaning transition, when the neonate switches from a diet of milk to solid food [18].

Although the high rate of cellular growth in cancer would suggest that arginine synthesis is essential, the role of arginine biosynthesis in cancer is poorly understood. Several cancer types are characterized by low ASS1 expression, including malignant melanoma, hepatocellular carcinoma, mesothelioma, and prostate cancer [13]. In these cancers, the promoter of the ASS1 gene is usually epigenetically silenced [11]. Silencing of ASS1 in these cancers is associated with tumor progression, resulting from increased pyrimidine synthesis, caused by a higher availability of aspartate [19]. Since ASS1-low tumors rely on extracellular arginine for their survival, arginine deprivation therapy, by using arginine-catabolizing enzymes like pegylated arginine deiminase and recombinant arginase, is currently being investigated in several clinical trials $[20,21]$. In contrast, other types of cancer, such as colorectal cancer, show an increase in the expression of ASS1 [11, 13, 22].

Recent reports suggest a role for increased ASS1 expression in the growth and survival of colorectal cancer cells [23]. Given the fact that arginine is known to be an important amino acid for tumor growth [24-26], modulation of arginine synthesis could be a therapeutic option to inhibit cancer growth. Additionally, stimulation of arginine synthesis might facilitate epithelial repair in case of a defective intestinal epithelial barrier.

In the context of epithelial repair, it has been shown that Ass1 whole-body heterozygous mice are more susceptible to irradiation, and particularly suffer from a decreased regenerative capacity of the small intestine [27]. When Asl, the enzyme that is the ultimate step in arginine synthesis, is deleted from epithelial cells, in combination with an arginine-free diet, mice treated with dextran sodium sulfate develop more severe intestinal inflammation [28], and silencing of Asl inhibits in vitro colorectal cancer cell growth [29].

Although the current literature suggests that ASS1 contributes to intestinal repair and tumorigenesis, its exact function remains unclear. In the present study, we carefully investigated the role of epithelial Ass 1 in intestinal repair and oncogenesis in vitro and in vivo. We utilize murine models where Ass 1 is specifically deleted from intestinal epithelium as well as human colorectal adenomas and cancer tissue.

\section{MATERIALS AND METHODS}

\section{Patient material}

Fresh samples of adenomas and adjacent healthy tissue were collected from patients and snap-frozen immediately after resection in the endoscopy program for the removal of large $(>1 \mathrm{~cm})$ colorectal adenomas at the Amsterdam University Medical Centers (location AMC). All patients provided written informed consent (METC2015_206). mRNA was isolated from the tissue samples by mechanical disruption, using the FastPrep-245 G (MP Biomedicals) in combination with Lysis Tubes S (Qiagen, Cat No./ID: 19091) two times for $1 \mathrm{~min}$, followed by the Allprep DNA/RNA Universal kit (Qiagen, ID 80204).

Paraffin-embedded tissue samples were obtained from the Department of Pathology, Leiden University Medical Center (LUMC, Leiden, the Netherlands), used according to the guidelines of the Medical Ethical Committee of the LUMC, as previously described [30].

\section{Animals}

All animal experiments were performed in accordance with the Animal Ethical Committee guidelines of the Academic Medical Center in Amsterdam, the Netherlands (permit number PVA235/ALC235AC-G). Mice were given ad libitum access to water and standard mouse chow (Teklad 2916, Envigo, Huntingdon, UK) or arginine-free chow (modified C 1069 Amino acids diet, Altromin, Lage, Germany). Mice were housed in a specific pathogen-free barrier environment with $12 \mathrm{~h}$ light/dark cycles. Pathogens were tested quarterly in sentinel animals housed in the same room. A tamoxifen-inducible and intestinal epithelium-specific knockout of Ass 1 was obtained, as described previously [31]. For $\mathrm{Cre}^{\text {ERT2 }}$-mediated recombination, mice were injected intraperitoneally with $2 \mathrm{mg}$ of tamoxifen (Sigma, Saint Louis, MO, USA) for 5 consecutive days. At $1 \mathrm{~h}$ prior to sacrifice all mice received an intraperitoneal injection of $100 \mathrm{mg} / \mathrm{kg}$ BrdU (Sigma-Aldrich, St Louis, MO, USA; $10 \mathrm{mg} / \mathrm{ml}$ in PBS). After sacrifice, the intestine was harvested, washed with cold PBS, and sectioned into proximal, middle and distal tissue of the small intestine. For further analysis, tissue was either snap-frozen or formalin-fixed and embedded in paraffin.

For the irradiation experiment in Fig. 1, wild-type C57BL/6 mice at 6 weeks of age were treated with 14Gy whole-body irradiation and euthanized at 24, 48, 72, and $96 \mathrm{~h}$ afterwards. For irradiation experiment described in Fig. 4, VillinCre ${ }^{\mathrm{ERT} 2}$ Ass $1^{\mathrm{wt} / \mathrm{wt}}$ and VillinCre $\mathrm{ERT}^{\mathrm{ERT}}$ Ass $1^{\mathrm{f} / \mathrm{fl}}$ were first injected with tamoxifen as described above, and 2 weeks later treated with $14 \mathrm{~Gy}$ whole-body irradiation. Mice were euthanized $96 \mathrm{~h}$ after irradiation. VillinCre ${ }^{\mathrm{ERT} 2} A s s 7^{\mathrm{fl} / \mathrm{fl}}$ mice were crossed to VillinCre ${ }^{\mathrm{ERT} 2} A p c^{\mathrm{fl} / \mathrm{fl}}$ mice in order to generate VillinCre ${ }^{\mathrm{ERT} 2} A s s 1^{\mathrm{f} / \mathrm{f}} A p c^{\mathrm{wt} / \mathrm{fl}}$ and VillinCre ${ }^{\mathrm{ERT}} A s s \mathrm{f}^{\mathrm{f} / \mathrm{fl}} A p c^{\mathrm{fl} / \mathrm{fl}}$ mice. VillinCre ${ }^{\mathrm{ERT} 2} A s s 7^{\mathrm{fl} / \mathrm{fl}} A p c^{\mathrm{wt} / \mathrm{fl}}$ heterozygous mice were euthanized 16 weeks after tamoxifen-induced recombination. Adenomas were counted in formalin-fixed tissue through a stereoscopic microscope. VillinCre ${ }^{\text {ERT2 }} A s s 1^{\mathrm{f} / f / 1} A p c^{\mathrm{f} / f \mathrm{l}}$ homozygous mice were euthanized 5 days after tamoxifen induction. VillinCre ${ }^{\mathrm{ERT} 2} A s s \mathrm{f}^{\mathrm{fl/f}} A p \mathrm{C}^{\mathrm{fl} / \mathrm{fl}}$ mice fed an arginine-free diet were euthanized 4 days after tamoxifen induction.

\section{Mouse intestinal-crypt isolation and organoid culture}

Small intestinal single crypts were isolated from C57BL/6, VillinCre ${ }^{\mathrm{ERT} 2} \mathrm{Apc} \mathrm{c}^{\mathrm{f} / \mathrm{fl}}$ (two types: exon $15 A p c^{15 l o x / 15 l o x}$ and exon $14 A p c^{5805 / 5805}$ separately tested), VillinCre ${ }^{\mathrm{ERT} 2} A p c^{\mathrm{f} / \mathrm{fl}} \mathrm{Kras}^{\mathrm{G} 12 \mathrm{D} / \mathrm{wt}}$, VillinCre ${ }^{\mathrm{ERT} 2} A s s \mathrm{f}^{\mathrm{f} / \mathrm{fl}}, \mathrm{VillinCre}^{\mathrm{ERT2}} A p c^{\mathrm{f} / \mathrm{fl}} A s \mathrm{f}^{\mathrm{f} / \mathrm{fl}}$, and Trp53 $3^{\mathrm{F2}-10 / 22-10}$ mice, and cultured in Matrigel (BD, Franklin Lakes, NJ, USA). Crypts were harvested by incubating opened small intestines in PBS containing 2 mM EDTA. The epithelium was released by vigorous shaking and crypts were separated by using a $70 \mu \mathrm{m}$ cell strainer. Single crypts were cultured in EGF, Noggin, R-spondin (ENR) medium, containing Advanced DMEM medium (Invitrogen/Thermo Fisher, Waltham, MA, USA) supplemented with $1 \%$ penicillin/streptomycin, 1\% HEPES buffer, and 1\% GlutaMAX, $50 \mathrm{ng} / \mathrm{ml} \mathrm{EGF,}$ $20 \%$ Noggin conditioned medium, 10\% R-spondin conditioned medium, $1 \mathrm{X}$ B-27 supplement, $1 \mathrm{X} \mathrm{N}-2$ supplement (all from Invitrogen), and $1.25 \mathrm{mM} \mathrm{N}$ acetylcysteine (Sigma). The organoids were then passaged weekly by mechanical disruption. Organoids with shRNAs against Smad4 and Trp53 were generated as previously described [32, 33]. Cre-mediated recombination in organoids was established by adding $1 \mu \mathrm{g} / \mathrm{ml}$ 4-hydroxytamoxifen to the culture medium for $24 \mathrm{~h}$. Photographs were taken with a Leica DMi8 microscope and analyzed with ImageJ (version 1.52p, http://imagej.nih.gov/ij/).

Single-cell clonogenicity experiments were performed as previously described [33]. In short, Matrigel was dissolved using cell recovery solution for $30 \mathrm{~min}$ on ice. Next, organoids were dissociated to single cells after 7 min of $37^{\circ} \mathrm{C}$ incubation with TrypLE (Gibco/Thermo Fisher). The absolute number of cells per condition was equalized using a particle counter (Zseries, Beckman Coulter, Fullerton, CA, USA) and 20,000 cells were plated in a 48-well plate. The number of outgrowing organoids was quantified 3-5 days after seeding, and presented as mean number of four wells.

\section{RNA extraction and qRT-PCR}

RNA was extracted from organoids using the Isolate II RNA Mini Kit (Bioline, London, UK) following the manufacturer's instructions. The intestinal tissue RNA was extracted with TRI Reagent (Sigma-Aldrich). Complementary DNA was synthesized from mRNA using $10 \mu \mathrm{M}$ Oligo-dT (ThermoFischer Scientific), $5 \mu \mathrm{g} / \mathrm{ml}$ random hexamer primers (Promega, Madison, USA), $1 \mathrm{mM}$ DNTP-mix, $20 \mathrm{U} /$ reaction RiboLock RNase, and $100 \mathrm{U} /$ reaction RevertAid reverse transcriptase (all ThermoFischer Scientific). Quantitative RT-PCR was performed on a CFX96TM Real-Time System (Bio-Rad Laboratories, Hercules, CA, USA) using Sensifast SYBR green (Bioline) according to the manufacturer's protocol. mRNA levels were normalized against the indicated reference gene and relative gene expression was calculated with the $2^{-\triangle \Delta C T}$ method [34].

For the microarray, RNA was amplified using a TotalPrep RNA amplification kit for Illumina (lllumina, San Diego, CA, USA) and labeled using a CRNA labeling kit for Illumina Arrays (Illumina, San Diego, CA, USA), followed by hybridization with Illumina Ref8 v2.0 mouse slides, following the manufacturer's protocol. Expression profiles were deposited in the GEO repository GSE179777. Initial normalization was performed using Genome studio software (v2.0, Illumina, San Diego, CA, USA). Further analysis was done with R2 Bioinformatics platform (http://r2.amc.nl, AMC, Amsterdam, The Netherlands). 


\section{Western blot}

Samples were run on 10\% SDS-PAGE gels under reducing conditions and then transferred to nitrocellulose membranes (GE Health Care, Zeist, The Netherlands). Membranes were blocked by incubation in 5\% BSA in TBST (TBS $+0.1 \%$ Tween-20) for $2 \mathrm{~h}$ at room temperature (RT) and subsequently incubated with anti-mmASS1 $(1: 10,000)$ [35], anti-hsASS1 (1:300, clone C104588, Sigma, Deisenhofen, Germany), or $\beta$-actin (1:100,000, clone AB1978, Sigma, Deisenhofen, Germany) antibodies in 2\% BSA in TBST overnight at $4{ }^{\circ} \mathrm{C}$. After incubation membranes were washed three times with TBST, incubated with HRP-conjugated secondary antibodies (1:2000, Dako) in $2 \%$ BSA in PBST for $2 \mathrm{~h}$ at RT. Expression was detected by Lumilight Plus (Roche). When combining proteins of similar $\mathrm{kDa}$, blots were stripped in stripping buffer (ThermoFischer Scientific) for $10 \mathrm{~min}$ at RT and incubated with the other antibody of the same $k D a$ as described above.

\section{HPLC}

Blood was collected into heparin-coated tubes and centrifuged at $500 \mathrm{~g}$ for 5 min at $4{ }^{\circ} \mathrm{C}$. Plasma was added to sulfosalicylic acid, vortexed, and stored at $-80^{\circ} \mathrm{C}$. Amino acid concentrations were determined by HPLC as previously described [36].

\section{Stable-isotope incubation and LC-MS analysis}

Organoids were incubated for $96 \mathrm{~h}$ in ENR medium enriched with stableisotope-labeled L-citrulline (ureido- ${ }^{13} \mathrm{C} ; 3,3,4-\mathrm{D}_{3}$; Buchem, The Netherlands) or stable-isotope-labeled L-aspartic acid $\left({ }^{13} \mathrm{C} 4\right.$; D3; $15 \mathrm{~N}, \mathrm{CDNLM}$ 6803-PK; Buchem, The Netherlands). Thereafter, culture media and cell pellets were collected and stored at $-80^{\circ} \mathrm{C}$. Kinetics were investigated by measuring isotope-labeled intermediates with liquid chromatography tandem mass spectrometry (LC-MS/MS) as previously described [37].

\section{Griess test}

Griess reagent containing $2.3 \mathrm{ml}$ phosphoric acid (85\%), $1 \mathrm{~g}$ sulfanilamide, $0.1 \mathrm{~g}$ naphtylethylenediamine (both Sigma, Deisenhofen, Germany), and $97.7 \mathrm{ml}$ water. Standards from 0 to $1000 \mu \mathrm{M}$ were prepared from sodium nitrite ( $\mathrm{NaNO}_{2}$; Merck, Darmstadt, Germany). Griess reagent was added in a 1:1 ratio to medium samples and standards. Absorbance was measured at $540 \mathrm{~nm}$ in a BioTek Synergy HT microplate reader (BioTek Instruments, Winooski, VT, USA).

\section{Immunohistochemistry}

Paraffin-embedded tissue was sectioned freshly $(4.5 \mu \mathrm{m})$ and dried overnight at $37^{\circ} \mathrm{C}$. Slides were deparaffinized with xylene and rehydrated in a graded series of ethanol. Endogenous peroxidase activity was blocked with $3 \% \mathrm{H}_{2} \mathrm{O}_{2}$ in methanol. For antigen retrieval, tissue was cooked in $0.01 \mathrm{M}$ sodium citrate solution ( $\mathrm{pH} 6.0$ ) for $20 \mathrm{~min}$. Non-specific binding was prevented by incubation with PBT (phosphate-buffered saline, bovine serum albumin $10 \mathrm{mg} / \mathrm{ml}$, and Triton X-100 $0.1 \%$ ). Tissue sections were incubated overnight with a primary antibody.

Mayer's hematoxylin (Sigma-Aldrich) was used as nuclear counter stain. The following antibodies were used: anti-mmASS1 (1:2000) [35], antihsASS1 (1:2000, clone C104588; Sigma, Deisenhofen, Germany), and antiBrdU (1:500, clone BMC9318; Roche, Woerden, The Netherlands). Images were captured with an Olympus BX51 microscope.

\section{Statistical analysis}

Data are presented as mean and standard error of the mean (SEM). Student's $t$-test was used to analyze data with two groups. One-way ANOVA with Tukey's multiple comparison test was performed for data with more than two groups. For statistical analysis, GraphPad Prism (version 7, La Jolla, CA: GraphPad Software Inc.) was used. A $p$-value $<0.05$ was considered statistically significant.

\section{RESULTS}

Ass 1 is highly expressed in repair of the intestinal epithelium and selectively upregulated in Apc-mutated organoids

To investigate alterations in pathways associated with amino acid metabolism in the regenerating intestinal epithelium, we exposed mice to $14 \mathrm{~Gy}$ whole-body gamma irradiation (Fig. 1A). In this model of damage and repair, the intestinal epithelium initially undergoes extensive cell death, resulting in a phase of epithelial repair 48-96 h after the irradiation with epithelial hyperproliferation and crypt multiplication through a process of elongation and fission. Microarray analysis on intestinal lysates at $96 \mathrm{~h}$ after irradiation revealed Ass1 to be highly significantly upregulated compared to non-irradiated mice (Fig. 1B). This was confirmed by qRT-PCR and immunohistochemistry (Fig. 1C, D). Hyperproliferative crypts showed especially strong cytosolic staining of ASS1 in line with previous observations [27]. The epithelium of nonirradiated wild-type mice expressed little to no ASS1 as expected. Since it has been suggested that ASS1 is similarly highly expressed in colorectal adenomas and carcinomas, we investigated mRNA expression of Ass 1 in murine organoids in which the main driver mutations associated with the adenoma-to-carcinoma sequence were modeled (Apc, Kras, Smad4, and Trp53) [38]. Ass1 expression was markedly upregulated in organoids carrying loss-of-function of tumor suppressor gene Apc (Fig. 1E), whereas the other mutations did not show elevated Ass 1 expression. Partial or complete loss of the tumor suppressor genes Smad4 and Trp53 tended to lower Apc-induced Ass 1 expression (Fig. 1E). Increased expression of ASS1 in $A p C^{-1-}$ organoids was confirmed at the protein level (Fig. 1F, G). In conclusion, only the Apc mutation upregulated Ass 1 in intestinal organoids, whilst mutations in Kras, Smad4, and Trp53 did not. This suggests that upregulation of ASS1 is specifically associated with activation of the Wnt pathway in intestinal epithelial cells.

\section{Loss of Apc affects multiple genes associated with the urea cycle}

Since Ass 1 is upregulated after Apc loss, we next investigated the effect of loss of $A p c$ on pathway components and associated genes of the urea cycle by qRT-PCR. Many genes that are part of the urea cycle, as well as genes associated with glutamate metabolism, proline metabolism, and polyamine synthesis (Supplemental Fig. 1A) were differentially expressed after loss of Apc (Fig. 1H). Expression of Arg2, Nos2, and Otc, central components of the urea cycle that are involved in conversion of arginine, was reduced in the context of Apc loss (Fig. $1 \mathrm{H}$ and Supplemental Fig. 1B). Furthermore, known arginine transporters, which mediate uptake of arginine, were mostly downregulated $($ Fig. $1 \mathrm{H})$. Together, increased synthesis of arginine, and decreased conversion and decreased uptake of arginine suggest that Apc-deleted cells may be reliant on autologous synthesis of arginine.

\section{ASS1 expression correlates with APC mutations in CRC cell lines and upregulated in human adenomas}

Next, we measured ASS1 mRNA and ASS1 protein expression in human colorectal cancer cell lines with a known mutational profile, as performed previously by others [39]. The different cell lines expressed ASS1 to various degrees (Fig. 2A). We related the expression level of ASS1 to mutations in APC, KRAS, SMAD4, and TP53 in these cell lines and observed a significant correlation between ASS1 expression and APC mutations, but not for other mutations, microsatellite instability (MSI), or CpG island methylator phenotype (CIMP) status (Fig. 2B and Supplemental Fig. 2A, $B)$, in line with our findings in mouse organoids. In a publicly available gene expression dataset containing healthy and adenomatous tissue from patients (GDS2947 [40]), we observed increased ASS1 expression (Fig. 2C). In a cohort of RNA samples isolated from 60 adenoma and 8 carcinoma samples paired with healthy control tissues from the same patients (Fig. 2D) and in a separate cohort of paraffin-embedded tissue from 70 healthy, 12 adenoma and 75 stage III carcinoma patients, a similar increase of ASS1 protein expression was observed (Fig. 2E and Supplemental Fig. 2C). 
A

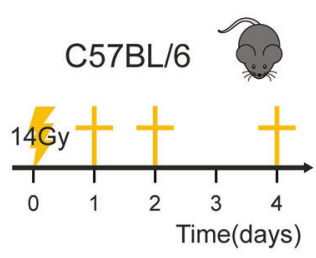

C

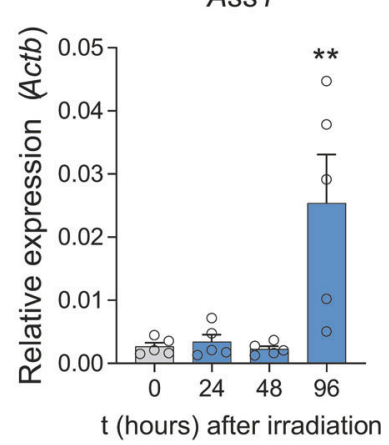

$\mathbf{E}$

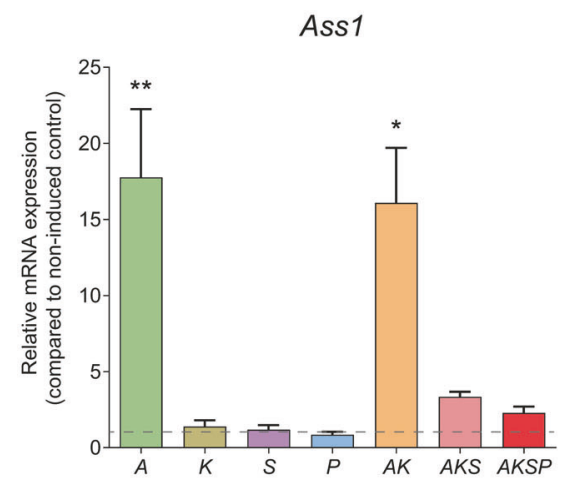

$\mathbf{F}$

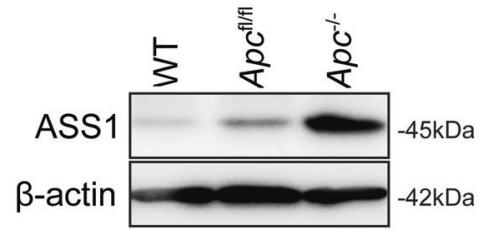

G

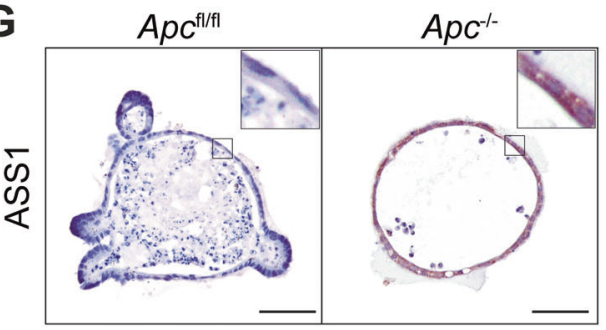

KEGG: Arginine biosynthesis
$t=24 h$ $\mathrm{t}=48 \mathrm{~h}$

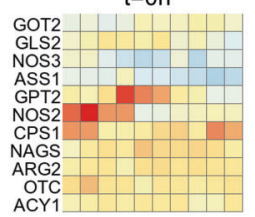

D
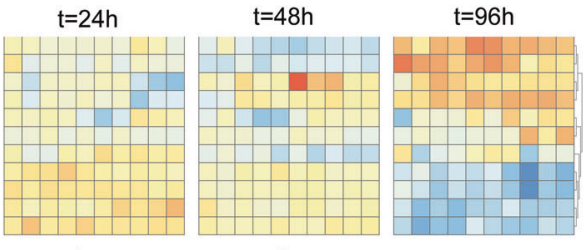

Score ${ }^{-3}$

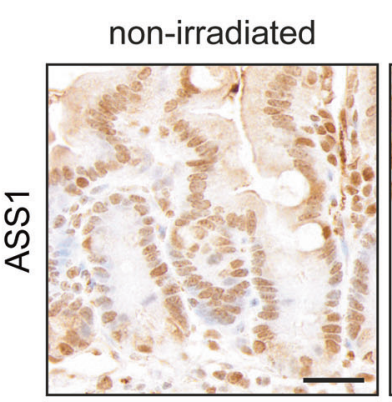

$96 \mathrm{~h}$

after irradiation

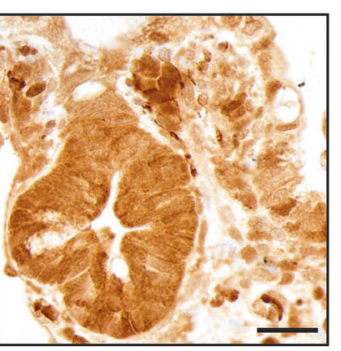

H
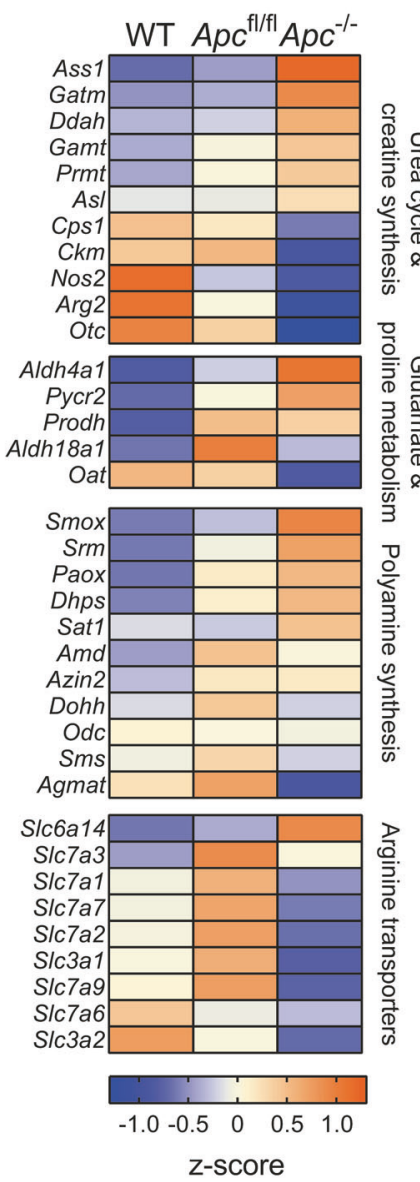

Loss of Apc results in altered arginine metabolism

In order to evaluate the effect of the Apc mutation in mouse intestinal epithelial organoids on arginine metabolism, we measured amino acid concentrations in the standard ENR medium of wild-type and $\mathrm{ApC}^{-/-}$organoids by HPLC. The Apc-deleted organoids showed an increased arginine and ornithine concentration, while aspartic acid, glutamic acid, and glutamine were decreased compared to wild-type organoids (Fig. 3A). This shows that the Apc mutation results in functional changes in amino acid consumption in intestinal epithelial cells. 
Fig. 1 Ass 1 expression increases during regeneration and upon loss of Apc. A Schematic overview of the mouse model. B Heatmap showing the expression of genes in the KEGG geneset 'Arginine biosynthesis', from RNA isolated from the intestines of irradiated mice at $t=0$, 24,48 , and $96 \mathrm{~h}$ ( $n=10$ mice per time point). C qRT-PCR for Ass1 on intestinal lysates from the same experiment ( $n=5 \mathrm{mice}$ per time point), $A c t b$ is used as a reference gene. D Immunohistochemistry for ASS1 in small intestine at $t=0$ and $t=96 \mathrm{~h}$ after irradiation. Micrographs show representative images. Scale bar represents $25 \mu \mathrm{m}$. E qRT-PCR for Ass1 in murine adenoma-to-carcinoma sequence organoids relative to noninduced control organoid (relative to Actb/Ppia), $\mathrm{A}=\mathrm{Apc}^{-/-}, \mathrm{K}=\mathrm{Kras}^{\mathrm{G} 12 \mathrm{D} /+}, \mathrm{S}=\mathrm{Smad4}$ shRNA, $\mathrm{P}=\operatorname{Trp53^{-/-}}$ (for single knockout) or Trp53 shRNA in combination with AKS. $p<0.05,{ }^{* *} p<0.01$ by student's $t$-test. F Western blot for ASS1 and beta-actin in wild type (WT; from C57BL/6 mice), VillinCre ${ }^{\mathrm{ERT} 2} A p c^{\mathrm{fl} / \mathrm{fl}}$ and VillinCre ${ }^{\mathrm{ERT} 2} \mathrm{Apc}^{-/-}$organoids. G Immunohistochemistry for ASS1 in VillinCre ${ }^{\mathrm{ERT} 2} \mathrm{Apc}^{\mathrm{fl} / \mathrm{fl}}$ and VillinCre ${ }^{\mathrm{ERT} 22} \mathrm{Apc}^{-/-}$ organoids. Micrographs show representative images. Scale bar represents $50 \mu \mathrm{m}$. H Heatmap showing qRT-PCR results for various urea cycle and creatine synthesis, glutamate and proline metabolism, polyamine synthesis, and arginine transporter genes.
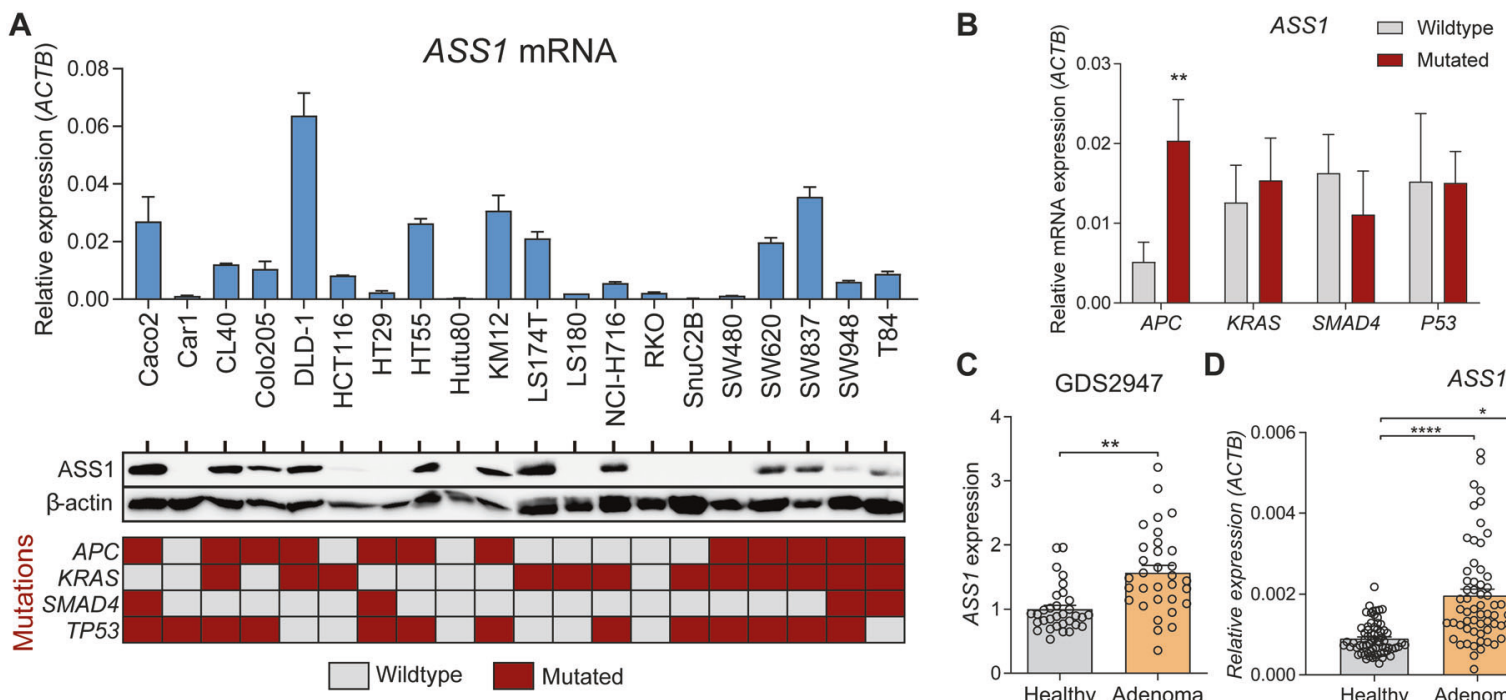

E

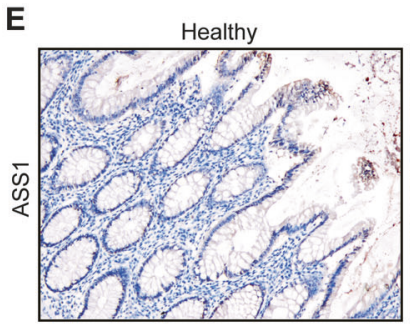

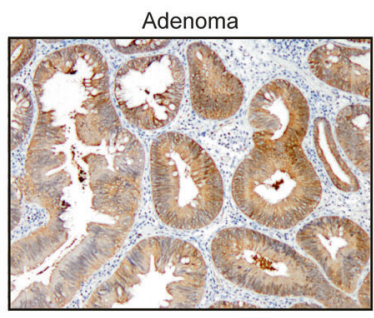

Carcinoma (Stage III)

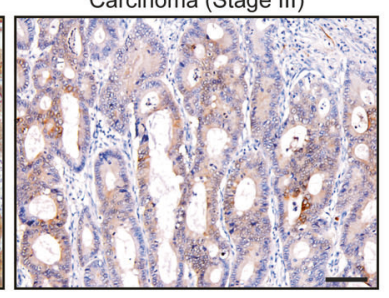

C

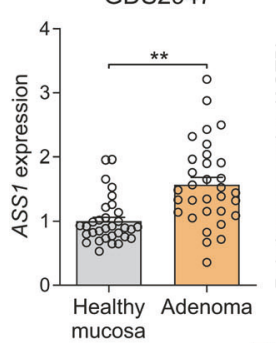

D

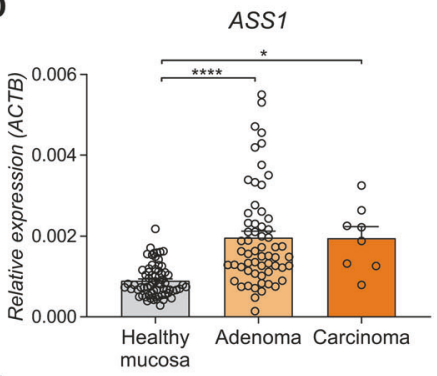

$\mathbf{F}$

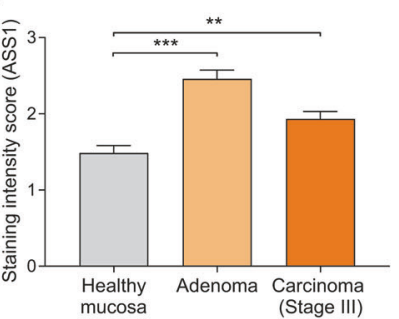

Fig. 2 ASS1 expression is upregulated and correlates with APC mutations in human colorectal adenomas and carcinomas. A ASS1 mRNA and ASS1 protein expression in 20 different colorectal cancer cell lines. Per cell line the mutational status of APC, KRAS, SMAD4, and TP53 is indicated below. B ASS1 mRNA expression in the same 20 colorectal cancer cell lines as in (A), separated by their mutational status. ${ }^{* *} p<0.01$ by Kruskal-Wallis test. C ASS1 expression in paired samples of normal mucosa and colorectal adenoma tissue $(n=32)$ from the publicly available expression dataset GDS2947. ${ }^{* * * *} p<0.0001$ by Wilcoxon signed rank test. D qRT-PCR for ASS1 in tissue from 60 adenoma and 8 carcinoma samples with paired controls. ${ }^{*} p<0.05,{ }^{* * * *} p<0.0001$ by Wilcoxon signed rank test. E immunohistochemistry for ASS1 in healthy ( $n$ $=70)$, adenoma $(n=12)$, and carcinoma $(n=75)$ tissue. Micrographs show representative images. Scale bar indicates $100 \mu \mathrm{m}$. $\mathbf{F} Q u a n t i f i c a t i o n$ of (E), which was scored in a blinded manner by two independent observers. $p<0.01,{ }^{* * *} p<0.001$ by one-way ANOVA with Tukey's multiple comparisons test.

Next, we incubated organoids with labeled citrulline $(13 C 1 ; 3,3,4-D 3)$ and used LC-MS to measure the effect of the altered expression of urea-cycle enzymes on the amino acid flux. The labeling in this synthesized citrulline was designed to lose one mass (from M4 to M3) after making a full cycle in the urea cycle (Fig. 3B and Supplemental Fig. 3A). We found increased labeling in argininosuccinate and arginine in Apc-mutant organoids, as was expected due to the increased expression of ASS1 (Fig. 3C). We observed a decrease in the ratio of M3/M4 arginine and citrulline in $A p c$-deleted organoids, suggesting inhibition of the flux of the urea cycle. Conversion of arginine into citrulline via ornithine was strongly inhibited, correlating with decreased expression of Arg2 and Otc in Apc-mutant versus wild-type organoids. No increase in NO production was seen as measured using the Griess test, which chemically detects nitrite ions (Supplemental Fig. 3D). The combined increase of arginine synthesis through ASS1 and decreased conversion of arginine to ornithine and citrulline would lead to an accumulation of arginine. We hypothesized that the arginine was being used for polyamine synthesis. However, no differential labeling was measured in spermine/spermidine. It has been suggested that knockdown or inhibition of Ass 1 reduces fumarate levels, which leads to inhibition of growth in colorectal cancer cell lines [23]. To test whether the upregulation of $A s s 1$ in the $\mathrm{Apc}^{-1-}$ organoids led to an increase in fumarate, we incubated the organoids with labeled aspartic acid (Supplemental Fig. 3B). However, no change in labeling was found in fumarate (Supplemental Fig. 3C). 
A

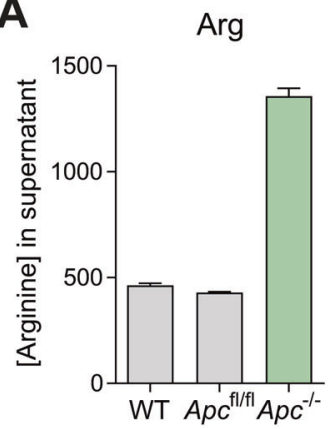

B

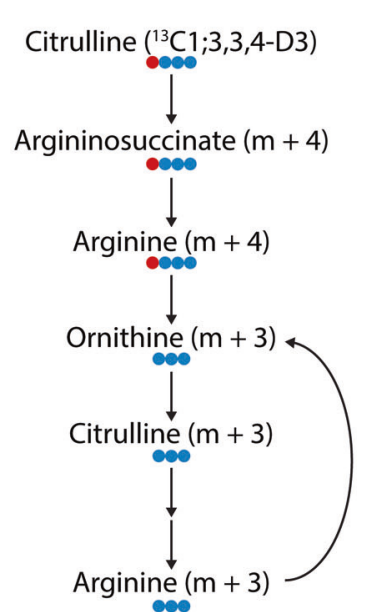

Asp

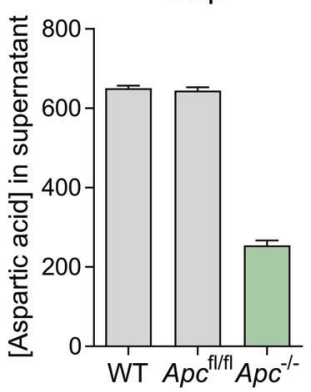

C
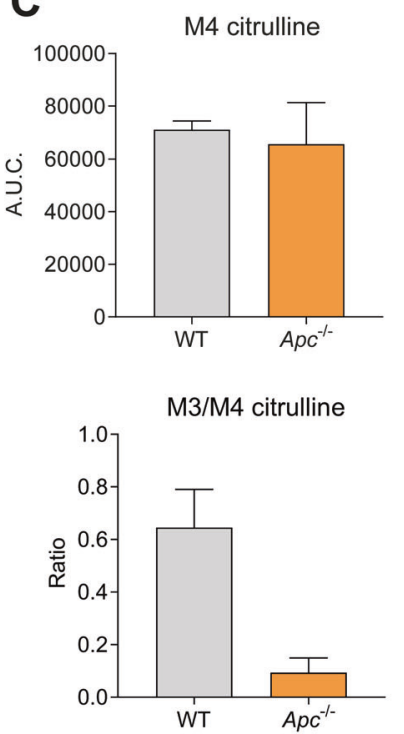

Cit

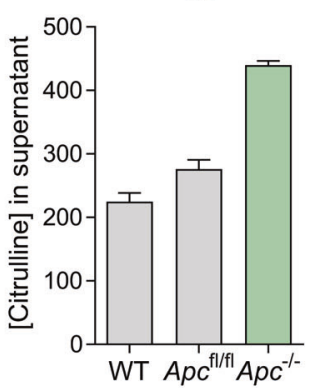

Glut

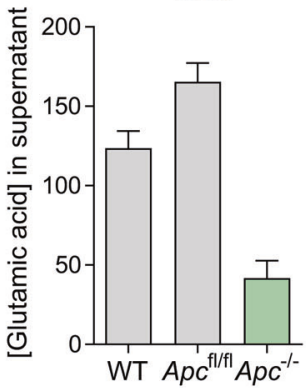

Orn

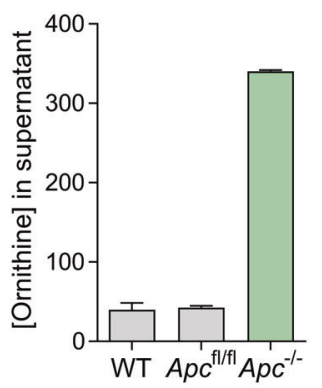

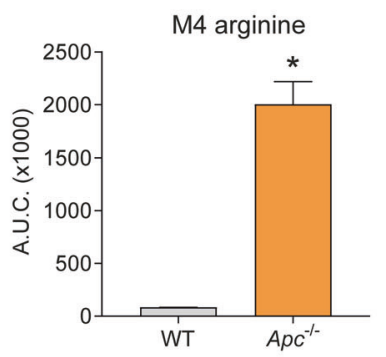
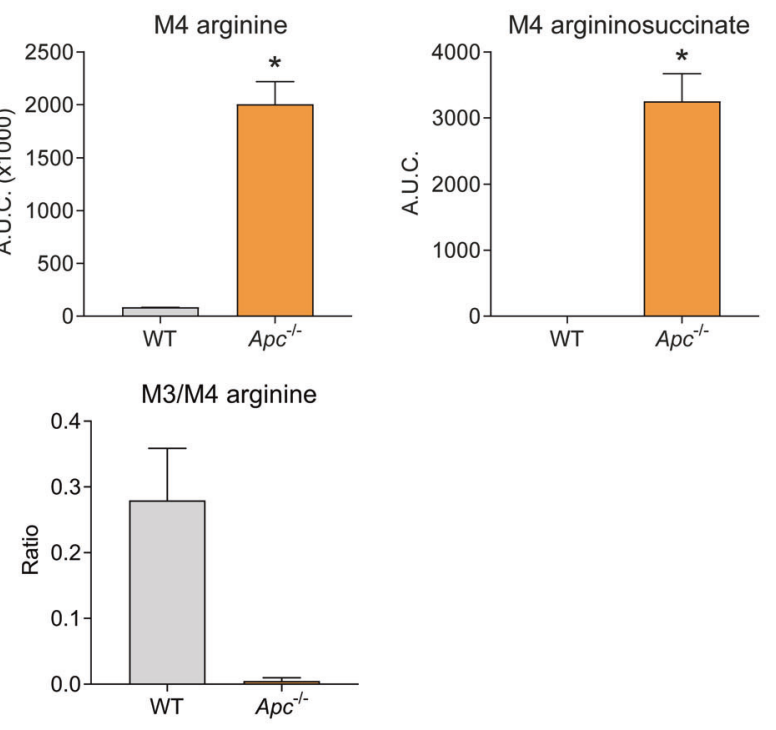

Fig. 3 Loss of Apc leads to altered amino acid consumption and synthesis. A Amino acid concentrations as measured by HPLC in supernatant of wild-type, VillinCre ${ }^{\mathrm{ERT} 2} A p \mathrm{C}^{\mathrm{f} / \mathrm{fl}}$, and VillinCre ${ }^{\mathrm{ER} \mathrm{P}_{2}} \mathrm{ApC}^{-/-}$organoids. B schematic overview of labeling. C LC-MS measurement of intracellular M4 citrulline, M4 arginine, and M4 argininosuccinate, in wild-type and VillinCre ${ }^{\mathrm{ERT} T 2} \mathrm{Apc}^{-/-}$organoids after incubation with labeled M4 citrulline (13C1;3,3,4-D3), and ratios between M3/M4-labeled citrulline and arginine. ${ }^{*} p<0.05$ by student's $t$-test.

Therefore, we concluded that upon deletion of $A p c$, citrulline is increasingly converted into arginine. Yet, this arginine is not further converted into other metabolites and the urea cycle does not flux, which ultimately results in the observed accumulation of arginine (Fig. 3A).

\section{Epithelial Ass 1 is not required for intestinal epithelial regeneration after irradiation}

We next set out to investigate the potential usage of excess arginine under in vivo physiological conditions. As mentioned above, whole-body Ass 1 heterozygosity has been shown to impair the regenerative capacity in the small intestine after irradiation [27]. We hypothesized that this effect might be due to epithelial overexpression of Ass 1 and excess arginine production. To test this, we crossed VillinCre ERT2 mice, in which Cre is activated after administration of tamoxifen in Villin-positive epithelial cells, to $A s s 1^{\mathrm{wt} / \mathrm{wt}}$ and $A s s 1^{\mathrm{fl} / \mathrm{fl}}$ mice to create mice in which Ass 1 can be specifically deleted from the intestinal epithelium [31]. At 2 weeks after intraperitoneal injection of tamoxifen, the mice were exposed to whole-body $14 \mathrm{~Gy}$ of ionizing radiation (Fig. 4A). Epithelial knockout of Ass 1 was efficient as shown by qRT-PCR on tissue lysates and immunohistochemistry (Fig. 4B, C). However, the villus length and the number of regenerating crypts per $\mathrm{mm}$ of intestine were not affected by the loss of Ass 1 in the intestinal epithelium (Fig. 4D, $\mathrm{E})$. These data suggest that epithelial upregulation of Ass 1 is not required for intestinal hyperproliferation observed after irradiation as a part of regenerative response.

\section{Epithelial expression of Ass 1 is not required for intestinal tumorigenesis}

To investigate the effect of loss of Ass 1 in a model of intestinal epithelial adenomatous transformation, we generated VillinCre ${ }^{\text {ERT2 }}$ Ass $1^{\mathrm{wt} / \mathrm{wt}} A p c^{\mathrm{f} / \mathrm{fl}}$ and VillinCre ${ }^{\mathrm{ERT2}} A s s 1^{\mathrm{f} / \mathrm{fl}} A p c^{\mathrm{f} / \mathrm{fl}}$ mice (Fig. 5A). In this model, the entire intestinal epithelial layer becomes hyperproliferative within 4 days after tamoxifen-induced recombination of $A p c$ [41]. Ass1 knockout did not have an effect on body weight (Fig. 5B), epithelial cell proliferation (Fig. 5C, D), or apoptosis (Fig. 5E).

To examine the role of epithelial Ass1 on spontaneous adenoma formation in $A p c$ heterozygous epithelium, we crossed these VillinCre ${ }^{\mathrm{ERT} 2}$ Ass $1^{\mathrm{wt} / \mathrm{wt}}$ and VillinCre ${ }^{\mathrm{ERT2}}$ Ass $1^{\mathrm{fl} / \mathrm{fl}}$ to $A p c^{\mathrm{fl} / \mathrm{fl}}$ mice. VillinCre ${ }^{\mathrm{ERT} 2} A p c^{\mathrm{wt} / \mathrm{fl}}$ heterozygous mice develop adenomas mostly in the small intestine approximately 16 weeks after tamoxifen induction (Fig. 5F). Loss of Ass1 did not affect body weight (Fig. $5 \mathrm{G})$. In adenomas of wild-type mice, ASS1 protein expression was increased (Fig. 5H; left panel), although not all adenomatous cells expressed high levels of ASS1. Ass $1^{-1-}$ mice showed clear loss of ASS1 in all Villin-positive cells at 16 weeks after induction (Fig. $5 \mathrm{H}$; right panel). At 16 weeks after recombination, we did not observe any effect of Ass1 knockout on the amount or size of the adenomas that were formed (Fig. 5l, J). In conclusion, loss of 
A

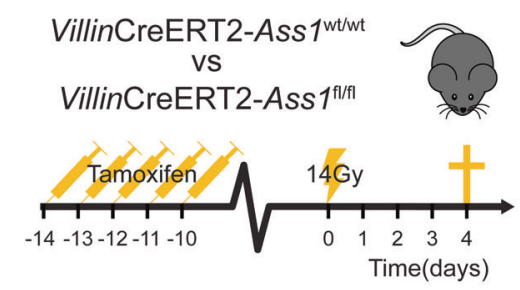

C

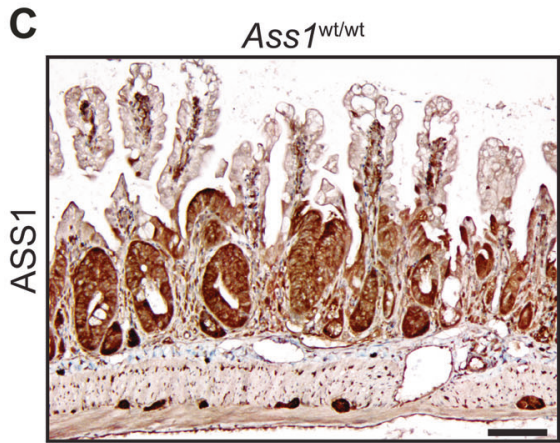

D

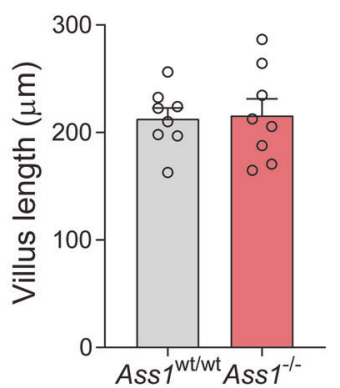

B

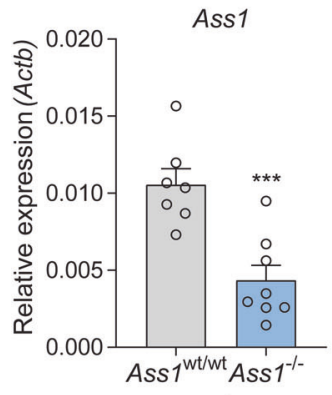

Ass1- $^{-1-}$

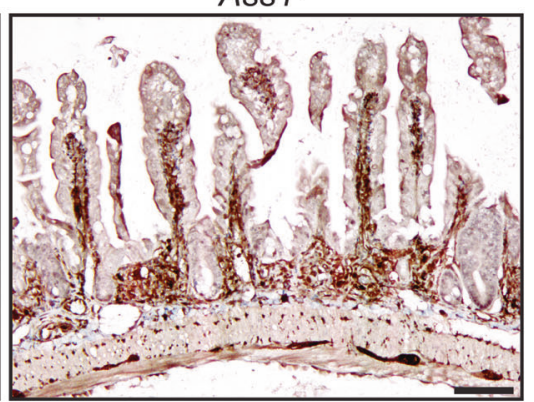

E

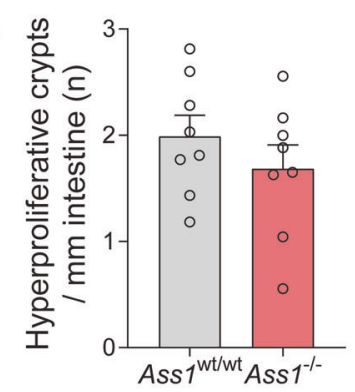

Fig. 4 Ass 1 knockout in the intestinal epithelium does not affect regeneration after damage by irradiation. A Schematic overview of the mouse model. B qRT-PCR for Ass 1 in small intestinal lysates of Ass $1^{\mathrm{wt} / \mathrm{wt}}$ and Ass $1^{-1-}$ mice $96 \mathrm{~h}$ after irradiation. Actb was used as a reference gene. ${ }^{* * *} p<0.001$ by Student's $t$-test. C Immunohistochemistry for ASS1 in small intestinal tissue of Ass $1^{\mathrm{wt} / \mathrm{wt}}$ and Ass $1^{-/-}$mice $96 \mathrm{~h}$ after irradiation. Representative images shown. Scale bar indicates $100 \mu \mathrm{m}$. D Average villus length. E Amount of hyperproliferative crypts per mm intestine. $n=8$ mice per group.

epithelial Ass1 does not affect epithelial transformation nor tumor progression after acute loss of both Apc alleles nor adenomagenesis in $A p c$ heterozygous epithelium in vivo. These data suggest that epithelial ASS1 is dispensable for the earliest stages of Apcdriven intestinal tumorigenesis.

\section{Ass 1 only contributes to growth under low-arginine conditions}

Although no visible phenotypic intestinal differences were observed in all the murine models we examined, we further investigated whether loss of ASS1 affects epithelial cells in in vitro organoid cultures. To this end, we isolated intestinal organoids from VillinCre ${ }^{\text {ERT2 }}$ Ass $1^{\text {wt/wt }}$, VillinCre ${ }^{\text {ERT2 }}$ Ass $1^{\text {fl/fl }}$, VillinCre ${ }^{\text {ERT2 }}$ Ass $1^{\mathrm{wt} / \mathrm{wt}} A p c^{\mathrm{fl} / \mathrm{fl}}$, and VillinCre ${ }^{\mathrm{ERT2}} A s s 1^{\mathrm{fl} / \mathrm{fl}} A p c^{\mathrm{fl} / \mathrm{fl}}$ mice. In these purely epithelial cell cultures, efficient knockout of Ass 1 was achieved (Fig. 6A, B) upon tamoxifen induction, confirmed by the inability to synthesize labeled arginine after incubation with labeled citrulline demonstrating the loss of ASS1 function (Fig. 6C). Expression levels of other genes in the urea cycle were unaffected by the loss of Ass1 (Fig. 6D). Loss of Ass1 also did not affect expression of Wnt target gene Axin2 or stem cell markers Lgr5 and Ascl2 (Supplemental Fig. 4A), neither did it affect stem cell function as assessed by seeding single cells in a clonogenic assay (Supplemental Fig. 4B). Notably, amino acid transporters S/c3a2 (encodes for $4 \mathrm{~F} 2$ cell-surface antigen heavy chain) and S/c7a3 (encodes for cationic amino acid transporter 3) showed up- and downregulation, respectively (Fig. 6E and Supplemental Fig. 4C). We reasoned that the upregulation of $S / c 3 a 2$ could compensate the loss of Ass 1 by allowing increased influx of arginine from the medium into the epithelial cells. In line with our in vivo findings, Ass 1 knockout did not affect organoid size in regular arginine-rich medium (Fig. 6F, G). However, when the organoids were cultured in arginine-low medium, Ass1-deficient organoids were significantly smaller in size. Also, the lumen of arginine-deprived organoids seemed to contain less cell debris, suggestive of a lower cell-turnover rate and the cell volume appeared flattened (Fig. 6F).

These data suggest that, in high-arginine conditions Ass1 does not contribute to organoid growth, possibly due to increased arginine uptake from the medium. However, in low-arginine conditions loss of Ass1 does affect organoid growth.

\section{Epithelial Ass 1 does not affect intestinal tumorigenesis in mice} fed an arginine-free diet

Since loss of epithelial Ass 1 did not inhibit tumorigenesis and hyperproliferation in vivo with arginine present in the diet, and we noted an effect on growth in low-arginine medium in vitro, we repeated the $A p c$ homozygous model (Fig. 5) with VillinCre ERT2 Ass $1^{\mathrm{wt} / \mathrm{wt}} A p c^{\mathrm{f} / \mathrm{fl}}$ and VillinCre ${ }^{\mathrm{ERT} 2} A s s 1^{\mathrm{f} / f \mathrm{l}} A p c^{\mathrm{f} / \mathrm{fl}}$ mice in argininefree conditions: Mice were fed arginine-free chow during 3 weeks 
A
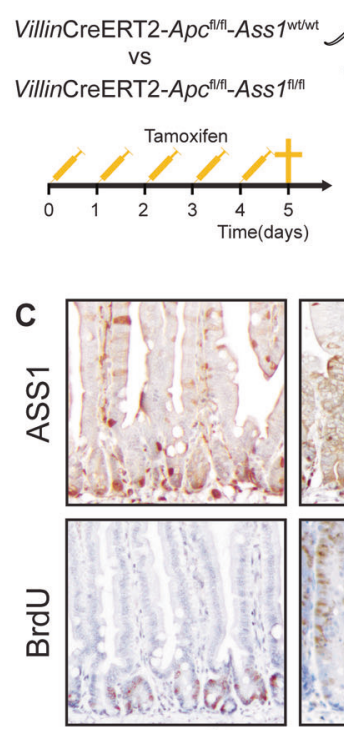

Ass 1wtwt $^{\text {with }}$ $A p c^{\text {wtwt }}$

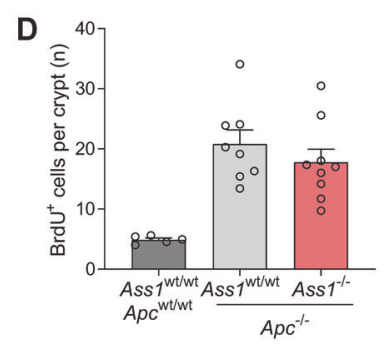

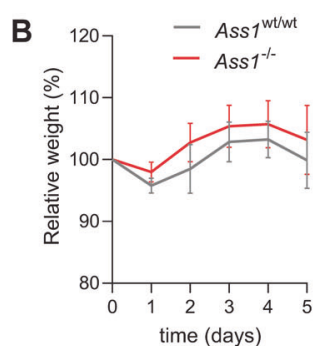
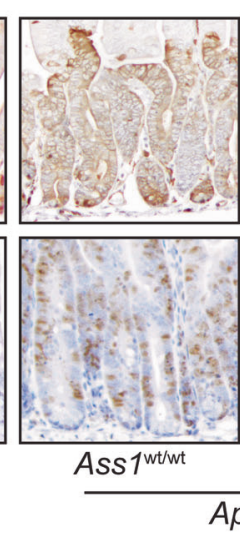

E

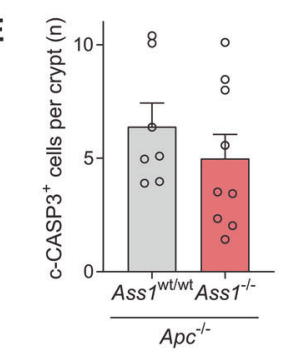

$\mathbf{F}$

VillinCreERT2-Apc ${ }^{\text {wtif }}-A s s 1^{\text {wtiwt }}$ vs

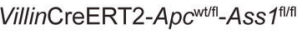

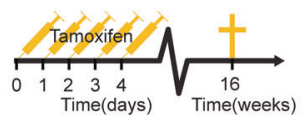

G

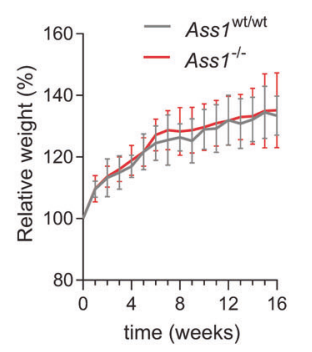

H

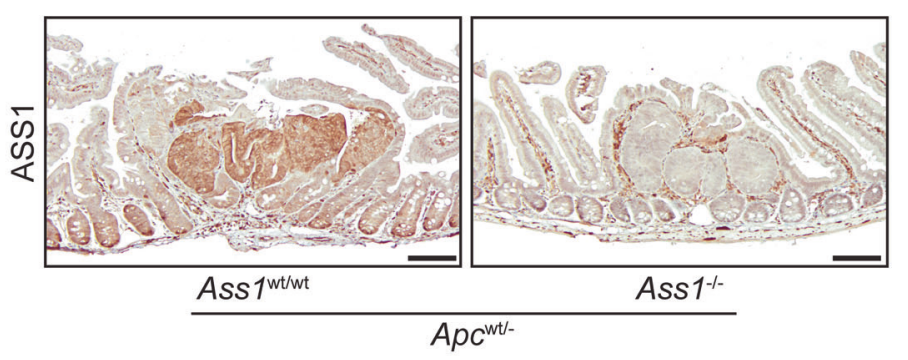

I

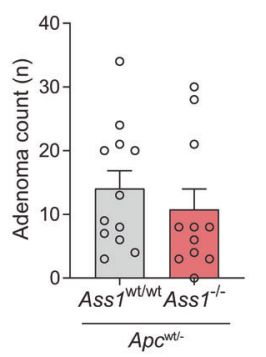

J

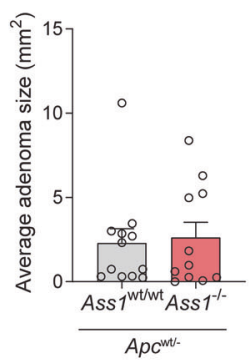

Fig. 5 Ass1 knockout in the intestinal epithelium does not affect tumorigenesis in vivo. A Schematic overview of the $A p c^{\mathrm{f} / \mathrm{fl}}$ mouse model. B Relative weight compared to start tamoxifen injections. C Immunohistochemistry for ASS1 (upper panels) and BrdU (lower panels) of Ass $1^{\text {wt } / \text { wt }}$ and Ass $1^{-1-}$ mice 5 days after recombination. Representative images are shown. Scale bar represents $50 \mu m$. D Amount of BrdU-positive cells per crypt in the small intestine. $\mathbf{E}$ Amount of cleaved caspase-3-positive cells per crypt in the small intestine. $\mathbf{F}$ Schematic overview of the Apc $c^{\text {wt/f }}$ mouse model. G Relative weight compared to start tamoxifen injections. $\mathbf{H}$ Immunohistochemistry for ASS1 in adenomas in Ass $1^{\text {wt/wt }}$ and Ass $1^{-/-}$mice. Scale bar represents $100 \mu \mathrm{m}$. I Amount of adenomas in both groups. J Average adenoma size.

prior to tamoxifen-induced recombination (Fig. 7A). No difference in weight was observed between the two groups, although the arginine-free diet seemed to lead to increased weight loss overall compared to mice fed regular chow (Figs. 7B and 5B). Although mice were deprived from arginine, the intestinal epithelium in Ass1-deficient mice showed the same levels of proliferation as Ass1 wild-type littermate controls (Fig. 7C). Furthermore, apoptosis was also not affected in VillinCre ${ }^{\mathrm{ERT} 2} A s s 1^{\mathrm{f} / \mathrm{fl}} A p c^{\mathrm{f} / \mathrm{fl}}$ mice fed an arginine-free diet (Fig. 7D). This shows that even in argininedeprived conditions Ass 1 does not play a role in the regenerating and adenomatous intestinal epithelium, excluding the possibility that excess arginine from the diet would obscure a potential role for Ass 1 in our previous experiments.

\section{Adaptation by the liver potentially compensates for intestinal loss of Ass 1}

Ass 1-deficient epithelial cells are unable to synthesize arginine; so in the situation of an arginine-free diet these cells must receive arginine from another source. It was shown previously that altered amino acid metabolism in the liver can compensate for loss of Ass 1 during development [31]. Therefore, we measured gene expression in livers from the whole-body irradiation experiment (Fig. 4). Lack of intestinal epithelial Ass 1 in this model led to a significant decrease in hepatic Arg2 expression (Fig. 8A), which would lead to decreased breakdown of arginine, to elevate systemic arginine levels in these mice. Plasma arginine levels were equal between wild-type and intestinal epithelial Ass1 knockout mice. Other amino acid levels were also unaltered, except for glutamine, which was decreased in the Ass1 knockout mice (Fig. 8B).

In VillinCre ${ }^{\mathrm{ERT} 2} A s s 1^{\mathrm{f} / / \mathrm{fl}} A p c^{\mathrm{f} / \mathrm{fl}}$ mice, Ass1 expression in the liver was significantly reduced upon loss of $A p c$ in the intestinal epithelium. However, the expression level of Ass 1 in the liver was not affected by the expression of Ass 1 in the epithelium, as liver Ass 1 expression was similar between $\mathrm{ApC}^{-/-} A s s 1^{\text {wt/wt }}$ and $\mathrm{ApC}^{-1-} A s s 1^{-/-}$mice (Fig. 8C). In contrast, Arg2 expression in the liver was clearly increased upon $A p c$ loss, whereas this increase was reduced upon combined loss of $A p C$ and Ass1 (Fig. 8C). These data indicate that the increased synthesis of arginine in the intestinal epithelium in the context of regeneration or $A p c$ knockout leads to systemic reduction of glutamine and hepatic alterations in amino acid metabolism, which can serve as a potential compensation mechanism.

\section{DISCUSSION}

It was previously suggested that Ass 1 contributes to intestinal regeneration and tumorigenesis, but our data from multiple in vitro and in vivo experiments do not support this hypothesis. Complete functional ablation of Ass 1 from cells of epithelial origin 
A

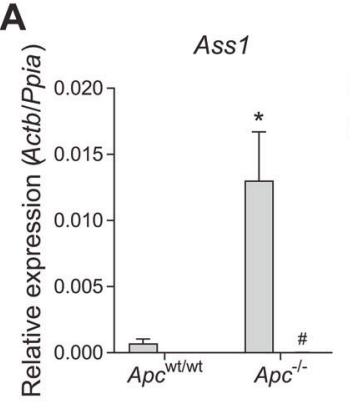

B

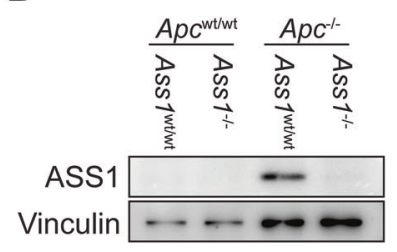

C
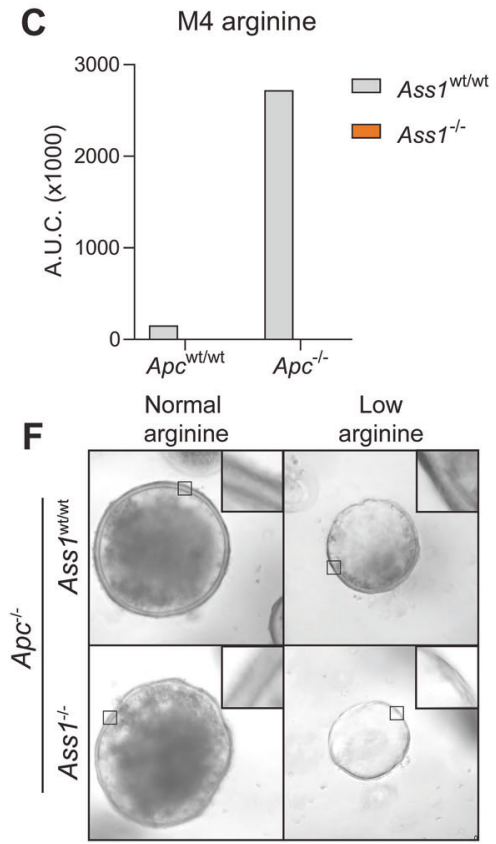

D
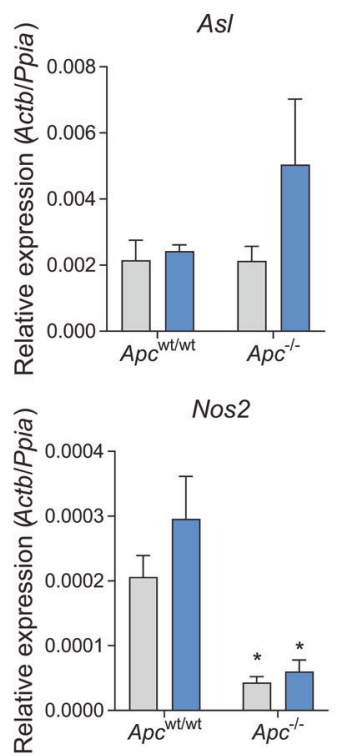

E

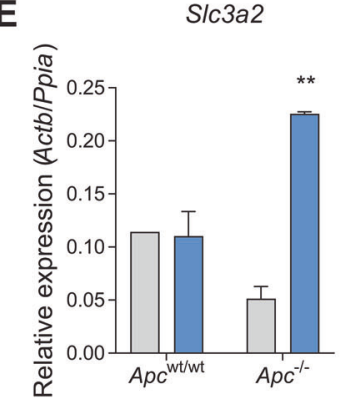

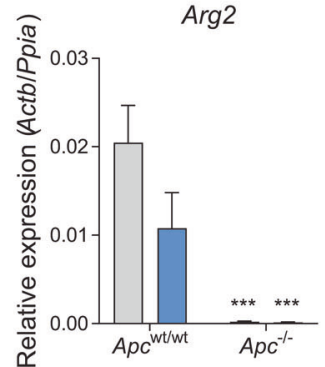

Otc

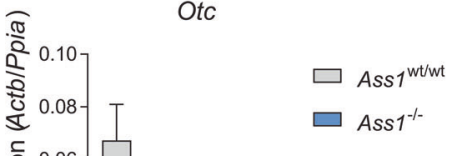

S/c7a3

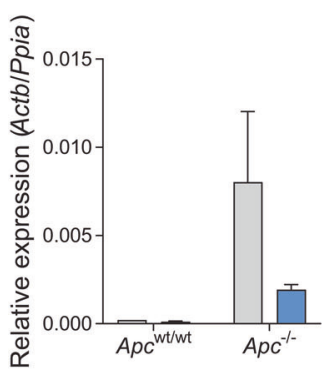

G

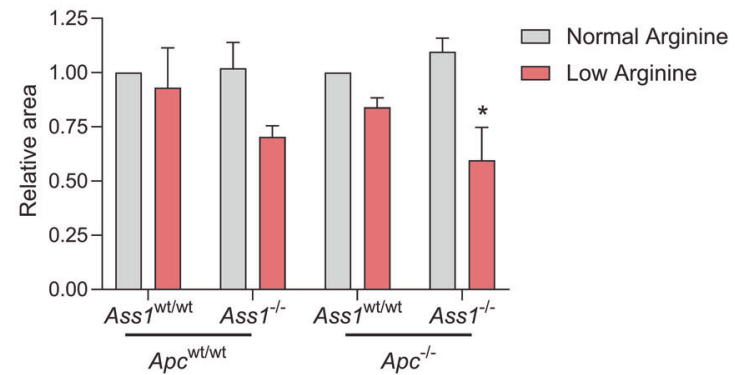

Fig. 6 Growth of Ass1-deficient small intestinal organoids is impaired in arginine-low conditions only and arginine transporters could compensate for loss of Ass1. A qRT-PCR for Ass1 in Ass1 and Apc knockout organoids. Actb and Ppia are used as reference genes. ${ }^{*} p<0.05$ compared to Ass $1^{\mathrm{wt} / \mathrm{wt}} A p c^{\mathrm{wt} / \mathrm{wt}}$ organoids, ${ }^{\#} p<0.05$ compared to Ass $1^{\mathrm{wt} / \mathrm{wt}} A p c^{-1-}$ organoids by one-way ANOVA with Tukey's multiple comparisons test. B Western blot for ASS1 and Vinculin in Ass1 and Apc knockout organoids. C Intracellular LC-MS measurements of M4 arginine in organoids cultured with M4 citrulline (U-13C;3,3,4-D3). D qRT-PCR for indicated urea-cycle genes. E qRT-PCR for indicated amino acid transporters. ${ }^{*} p<0.05,{ }^{* * *} p<0.001,{ }^{* * *} p<0.0001$ by one-way ANOVA with Tukey's multiple comparisons test. F Microscopic bright-field images of organoids cultured in regular and low-arginine medium. Representative images are shown. Scale bar represents $100 \mu \mathrm{m}$. G Quantification of organoid size cultured in regular and low-arginine medium ( $n=3$ independent experiments) ${ }^{*} p<0.05$ student's $t$-test.

had no effect on tumorigenesis in a mouse model that is representative with the mutational spectrum of $80 \%$ of sporadic human colorectal cancers. Also, we found no role for epithelial Ass 1 during regeneration in a model of irradiation-induced epithelial damage and repair. Ass1 expression is increased specifically by deletion of $A p c$ and the urea-cycle flux is arrested. The correlation we find between $A p c$ and Ass 1 is most likely mediated through translocation of beta catenin to the nucleus with subsequent activation of the Wnt target gene $C M y c$, which has been shown to bind to the promoter of Ass 1 and increase Ass 1 expression [42]. Other transcription factors that can indirectly be influenced by activation of the Wnt signaling pathway, such as HIF1alpha and ATF4, are likely to also influence Ass1 expression $[43,44]$.

The loss of Ass 1 in the context of an Apc mutation does seem to lead to intrinsic compensation by amino acid transporters and extrinsic compensation by distant organs like the liver. As we show, arginine transporters are upregulated in Ass1-deficient organoids allowing more arginine uptake from the medium. At the same time, serum glutamine levels are increased and hepatocytes alter their arginine metabolism, by which the amino acid demand in the intestinal tissue can be met. This is similar to 

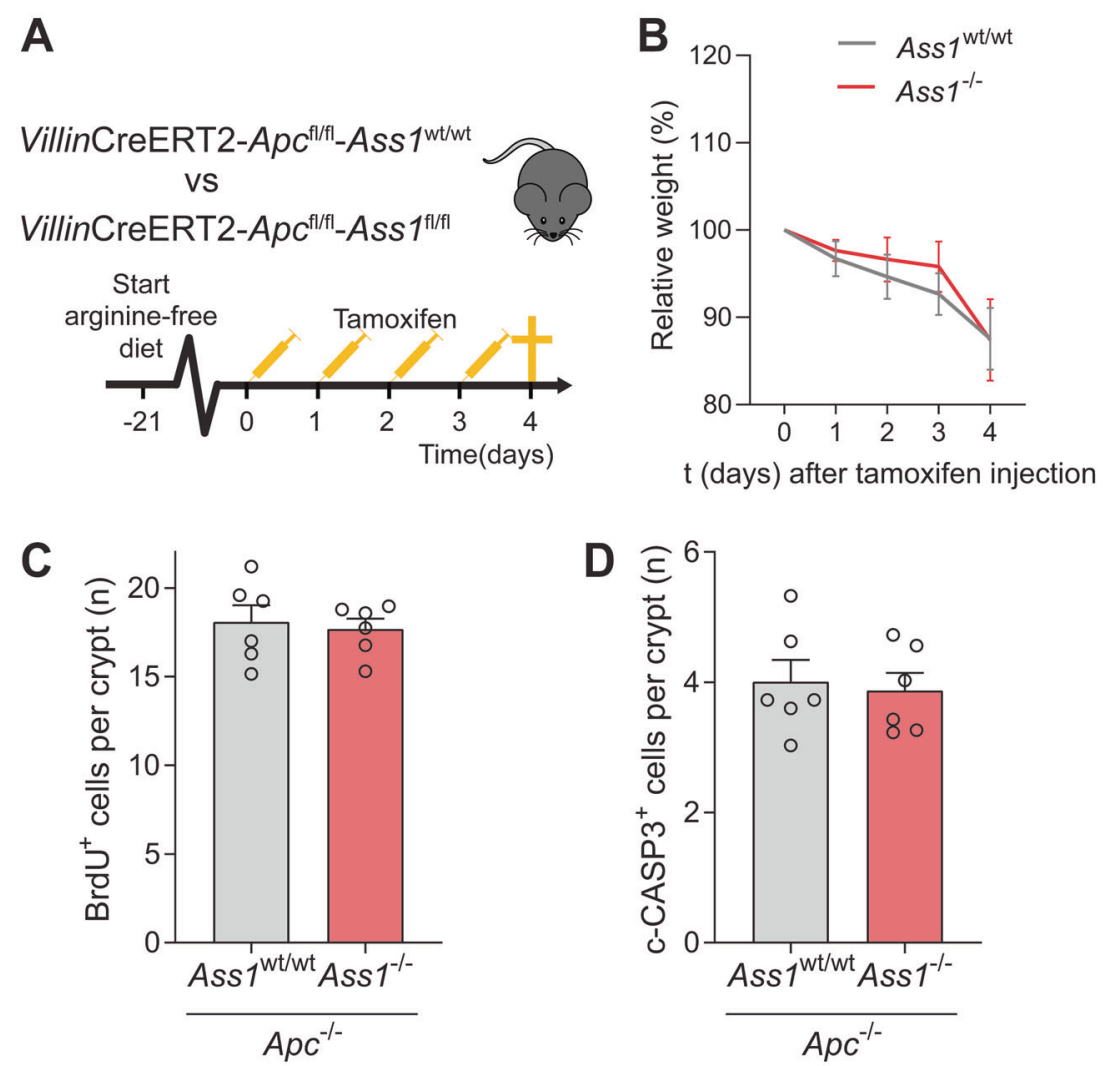

Fig. 7 Ass 1 knockout in the intestinal epithelium does not affect Apc-mediated hyperproliferation in mice fed an arginine-free diet. A Schematic overview of the mouse model. B Relative weight compared to start tamoxifen injections. C Amount of BrdU-positive cells per crypt in the small intestine. D Amount of cleaved caspase-3-positive cells per crypt in the small intestine.

what was already reported during embryogenesis, although there are major differences in the response. In our models, breakdown of arginine by arginase is inhibited in the liver, whereas in embryogenesis, hepatic expression of arginase is increased [31]. These differences may be explained by the fact that arginine is required for the developing embryo, whereas the adult body is not in need of the excess of arginine that is produced upon a loss of $A p c$. Besides, newborn mice are not fed arginine before the suckling-to-weaning transition has been completed, as the mother's milk does not contain any.

In the study of Miyamoto et al., in which Ass1 heterozygosity led to aggravated damage after irradiation [27], the heterozygosity was not cell-type specific. In our experiments, the homozygous loss of Ass1 was intestinal epithelium specific, with only Villinexpressing cells being affected. The effect of reduced synthesis of arginine in all cells apparently renders the body incapable of compensating for the loss, but this is not the case with our specific knockout. Although hepatic Ass1 did not seem to contribute to the compensation for intestinal loss in our study, Arg2 did. Thus, it may well be that the sum effect of body-wide Ass 1 heterozygosity in the study of Miyamoto et al. overloaded the compensatory mechanisms. In particular, non-epithelial intestinal cells, such as fibroblasts or immune cells, may play a role in this compensation, since they are in close vicinity to the epithelial cells and seem to express ASS1 in our experiments (Figs. $4 \mathrm{C}$ and $5 \mathrm{H}$ ), but this remains to be elucidated.

It is likely that the high expression of Ass 1 in intestinal epithelial cells during regeneration serves the purpose of optimizing cellular growth and proliferation. However, multiple compensatory mechanisms, either cell-autonomous or systemic, are available to rescue local loss-of-function as is the case with many fundamental biological processes. Besides, as was previously shown, loss of Ass 1 may lead to an increase in cell division by facilitating pyrimidine synthesis via CAD (carbamoyl-phosphate synthase 2, aspartate transcarbamylase, and dihydroorotase complex) activation, through increased aspartate availability [19]. In addition, the strong inhibition of arginase in the hyperproliferative intestinal epithelial cells may have a stronger effect on the arginine availability than the increased Ass1 expression [45].

A recent report has shown that some colorectal cancer cell lines have low ASS1 and OTC expression, which renders these cell lines arginine auxotrophic (dependant on extracellular arginine), similar to our Apc-Ass 1 knockout model [46]. This study shows that in a xenotransplantation model, arginine deprivation leads to inhibition of proliferation of the ASS1-low colorectal cancer cells. This is in contrast to our findings in vivo where loss of Ass 1 does not affect proliferation in an Apcmutated background. In xenotransplantation models, cancer cells are injected subcutaneously, which might explain the differences with our model. Native stromal cells in the intestine might compensate for Ass 1 loss in the epithelium, whilst subcutaneous tissue (mostly adipocytes and fibroblasts) might not provide compensation. Also, colorectal cancer cell lines generally have acquired a large amount of mutations, which can influence metabolic needs and thereby lead to a different response from our more selectively mutated $A p c$ model.

With regard to their arginine metabolism, hyperproliferative intestinal epithelial cells are reprogrammed in a similar way during the processes of embryonic development, regeneration after damage, and tumorigenesis. However, our results demonstrate that ASS1 is not essential for this reprogramming, since the functions related to ASS1 can be efficiently compensated for. An 
A

Ass1

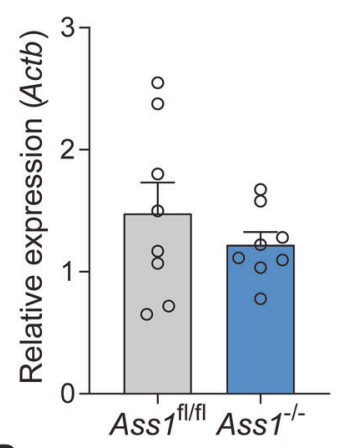

B

Arginine

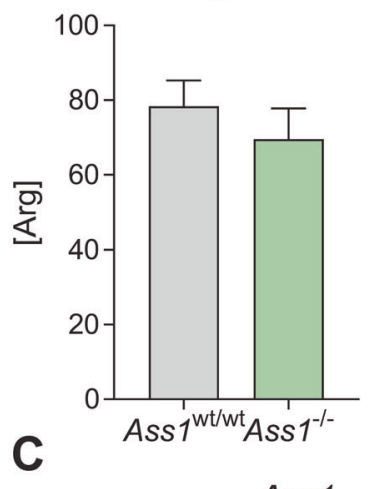

Ass1

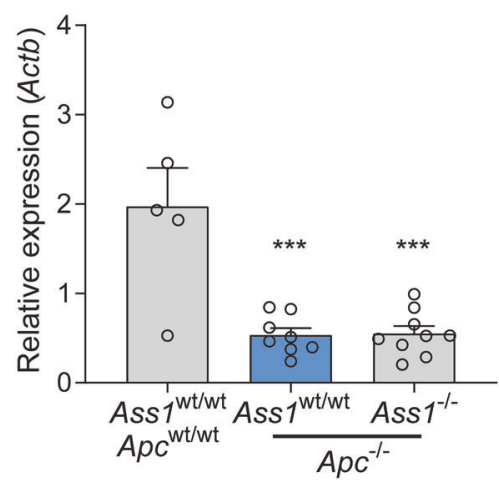

$\operatorname{Arg} 2$

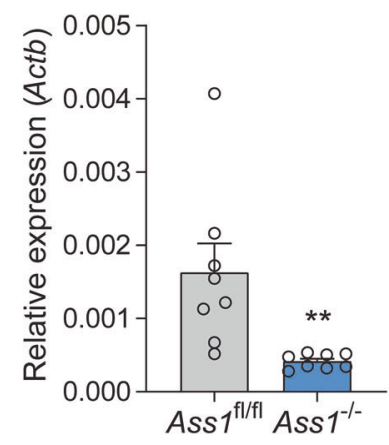

Citrulline

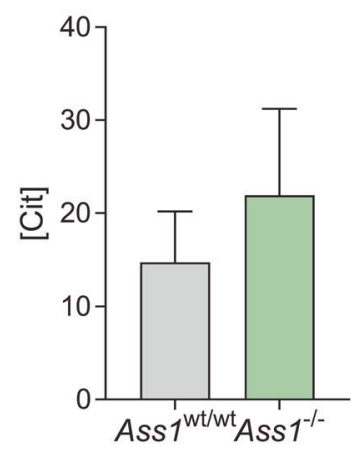

Otc

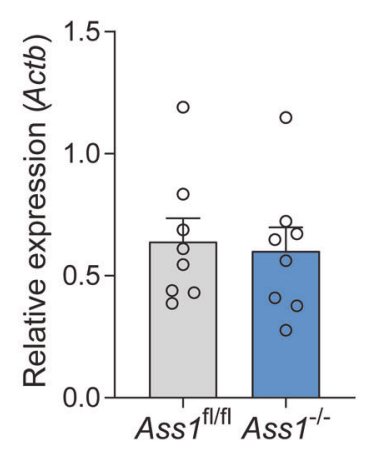

Ornithine

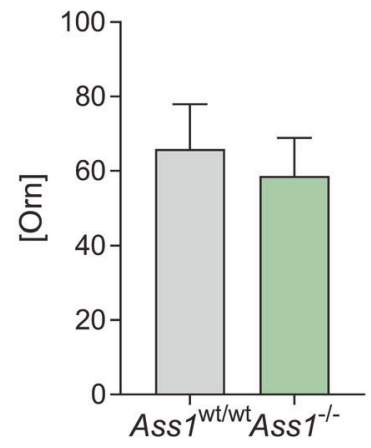

Nos2

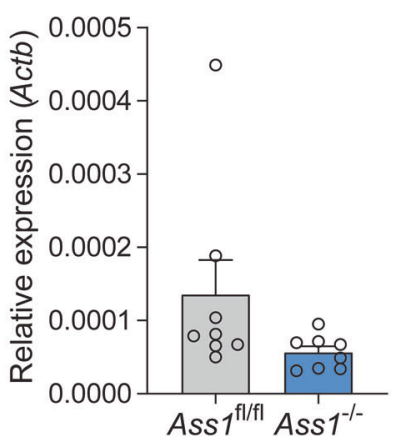

Glutamine

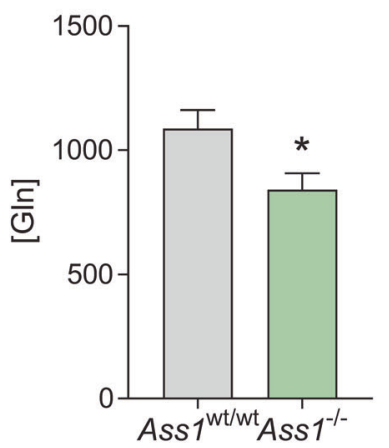

Arg2

Otc
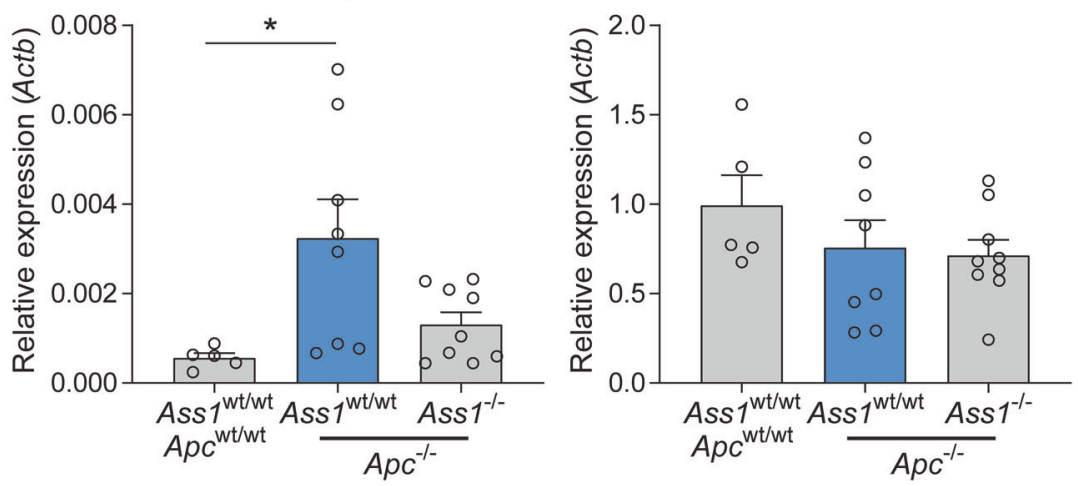

Fig. 8 Plasma glutamine levels and expression of urea-cycle enzymes in the liver, might compensate for intestinal loss of Ass1. A qRTPCRs for indicated genes in liver tissue from VillinCre ${ }^{\text {ERT2 }}$ Ass $1^{\text {wt } / \text { wt }}$ and VillinCre ${ }^{\text {ERT2 }}$ Ass $1^{-1-}$ mice $96 \mathrm{~h}$ after $14 \mathrm{~Gy}$ irradiation. Actb was used as a reference gene. ${ }^{* *} p<0.01$ by Student's $t$-test. B Plasma levels of indicated amino acids measured by HPLC from VillinCre ${ }^{\text {ERT2 }}$ Ass $1^{\text {wt/wt }}$ and VillinCre ${ }^{\text {ERT2 }}$ Ass $1^{-1-}$ mice $96 \mathrm{~h}$ after $14 \mathrm{~Gy}$ irradiation. ${ }^{*} p<0.05$ by Student's $t$-test. C qRT-PCRs for indicated genes in liver tissue from VillinCre ${ }^{\mathrm{ERT} 2} A s s 1^{\mathrm{wt} / \mathrm{wt}} A p c^{\mathrm{wt} / \mathrm{wt}}$, VillinCre ${ }^{\mathrm{ERT} 2} A s s 1^{\mathrm{wt} / \mathrm{wt}} A p c^{-1-}$, and VillinCre ${ }^{\mathrm{ERT} 2} A s s 1^{-1-} A p c^{-1-}$ mice, 5 days after induction. Actb was used as a reference gene. ${ }^{*} p<0.05$ by one-way ANOVA with Tukey's multiple comparisons test.

important consequence of this finding is that our data suggest that epithelial ASS1 may not be a potential therapeutic target for colorectal cancer treatment.

\section{DATA AVAILABILITY}

Data and materials are available through the accession number GSE179777 and the corresponding author on request.

\section{REFERENCES}

1. Potten CS, Owen G, Roberts SA. The temporal and spatial changes in cell proliferation within the irradiated crypts of the murine small intestine. Int J Radiat Biol. 1990;57:185-99.
2. Muncan V, Sansom OJ, Tertoolen L, Phesse TJ, Begthel H, Sancho E, et al. Rapid loss of intestinal crypts upon conditional deletion of the Wnt/Tcf-4 target gene c-Myc. Mol Cell Biol. 2006;26:8418-26.

3. Dekaney CM, Gulati AS, Garrison AP, Helmrath MA, Henning SJ. Regeneration of intestinal stem/progenitor cells following doxorubicin treatment of mice. Am J Physiol Gastrointest Liver Physiol. 2009;297:G461-70.

4. van Es JH, Sato T, van de Wetering M, Lyubimova A, Yee Nee AN, Gregorieff A, et al. DII ${ }^{+}$secretory progenitor cells revert to stem cells upon crypt damage. Nat Cell Biol. 2012;14:1099-104.

5. Ashton GH, Morton JP, Myant K, Phesse TJ, Ridgway RA, Marsh V, et al. Focal adhesion kinase is required for intestinal regeneration and tumorigenesis downstream of Wnt/c-Myc signaling. Dev Cell. 2010;19:259-69.

6. Dvorak HF. Tumors: wounds that do not heal. Similarities between tumor stroma generation and wound healing. N. Engl J Med. 1986;315:1650-9. 
7. Pavlova NN, Thompson CB. The emerging hallmarks of cancer metabolism. Cell Metab. 2016;23:27-47.

8. Warburg O. Über den stoffwechsel der carcinomzelle. Naturwissenschaften. 1924;12:1131-7.

9. Xiao F, Wang C, Yin H, Yu J, Chen S, Fang J, et al. Leucine deprivation inhibits proliferation and induces apoptosis of human breast cancer cells via fatty acid synthase. Oncotarget. 2016;7:63679-89.

10. Maddocks OD, Berkers CR, Mason SM, Zheng L, Blyth K, Gottlieb E, et al. Serine starvation induces stress and p53-dependent metabolic remodelling in cancer cells. Nature. 2013;493:542-6.

11. Delage B, Fennell DA, Nicholson L, McNeish I, Lemoine NR, Crook T, et al. Arginine deprivation and argininosuccinate synthetase expression in the treatment of cancer. Int J Cancer. 2010;126:2762-72.

12. Ward PS, Thompson CB. Metabolic reprogramming: a cancer hallmark even warburg did not anticipate. Cancer Cell. 2012;21:297-308.

13. Dillon BJ, Prieto VG, Curley SA, Ensor CM, Holtsberg FW, Bomalaski JS, et al. Incidence and distribution of argininosuccinate synthetase deficiency in human cancers: a method for identifying cancers sensitive to arginine deprivation. Cancer. 2004;100:826-33.

14. Okamoto R, Watanabe M. Role of epithelial cells in the pathogenesis and treatment of inflammatory bowel disease. J Gastroenterol. 2016;51:11-21.

15. Martini E, Krug SM, Siegmund B, Neurath MF, Becker C. Mend your fences: the epithelial barrier and its relationship with mucosal immunity in inflammatory bowel disease. Cell Mol Gastroenterol Hepatol. 2017;4:33-46.

16. Manfredo Vieira S, Hiltensperger M, Kumar V, Zegarra-Ruiz D, Dehner C, Khan N, et al. Translocation of a gut pathobiont drives autoimmunity in mice and humans. Science. 2018;359:1156-61.

17. Wu G, Morris SM Jr. Arginine metabolism: nitric oxide and beyond. Biochem J. 1998;336:1-17.

18. Hurwitz R, Kretchmer N. Development of arginine-synthesizing enzymes in mouse intestine. Am J Physiol. 1986;251:G103-10.

19. Rabinovich S, Adler L, Yizhak K, Sarver A, Silberman A, Agron S, et al. Diversion of aspartate in ASS1-deficient tumours fosters de novo pyrimidine synthesis. Nature. 2015;527:379-83.

20. Szlosarek PW, Steele JP, Nolan L, Gilligan D, Taylor P, Spicer J, et al. Arginine deprivation with pegylated arginine deiminase in patients with argininosuccinate synthetase 1-deficient malignant pleural mesothelioma: a randomized clinical trial. JAMA Oncol. 2017;3:58-66.

21. Tsai HJ, Jiang SS, Hung WC, Borthakur G, Lin SF, Pemmaraju N, et al. A phase II study of arginine deiminase (ADI-PEG20) in relapsed/refractory or poor-risk acute myeloid leukemia patients. Sci Rep. 2017;7:11253.

22. Rho JH, Qin S, Wang JY, Roehrl MH. Proteomic expression analysis of surgical human colorectal cancer tissues: up-regulation of PSB7, PRDX1, and SRP9 and hypoxic adaptation in cancer. J Proteome Res. 2008;7:2959-72.

23. Bateman LA, Ku WM, Heslin MJ, Contreras CM, Skibola CF, Nomura DK. Argininosuccinate synthase 1 is a metabolic regulator of colorectal cancer pathogenicity. ACS Chem Biol. 2017;12:905-11.

24. Gilroy $E$. The influence of arginine upon the growth rate of a transplantable tumour in the mouse. Biochem J. 1930;24:589-95.

25. Gonzalez GG, Byus CV. Effect of dietary arginine restriction upon ornithine and polyamine metabolism during two-stage epidermal carcinogenesis in the mouse. Cancer Res. 1991;51:2932-9.

26. Yeatman TJ, Risley GL, Brunson ME. Depletion of dietary arginine inhibits growth of metastatic tumor. Arch Surg. 1991;126:1376-81; discussion 1381-2.

27. Miyamoto T, Lo PHY, Saichi N, Ueda K, Hirata M, Tanikawa C, et al. Argininosuccinate synthase 1 is an intrinsic Akt repressor transactivated by p53. Sci Adv. 2017;3:e1603204.

28. Stettner N, Rosen C, Bernshtein B, Gur-Cohen S, Frug J, Silberman A, et al. Induction of nitric-oxide metabolism in enterocytes alleviates colitis and inflammation-associated colon cancer. Cell Rep. 2018;23:1962-76.

29. Huang HL, Chen WC, Hsu HP, Cho CY, Hung YH, Wang CY, et al. Silencing of argininosuccinate lyase inhibits colorectal cancer formation. Oncol Rep. 2017;37:163-70.

30. Paauwe M, Schoonderwoerd MJA, Helderman R, Harryvan TJ, Groenewoud A, van Pelt GW, et al. Endoglin expression on cancer-associated fibroblasts regulates invasion and stimulates colorectal cancer metastasis. Clin Cancer Res. 2018;24:6331-44.

31. Marion V, Sankaranarayanan S, de Theije C, van Dijk P, Hakvoort TB, Lamers WH, et al. Hepatic adaptation compensates inactivation of intestinal arginine biosynthesis in suckling mice. PLoS ONE. 2013;8:e67021.

32. Van Lidth de Jeude JF, Vermeulen JL, Montenegro-Miranda PS, Van den Brink GR, Heijmans J. A protocol for lentiviral transduction and downstream analysis of intestinal organoids. J Vis Exp. 2015;98:52531.

33. Smit WL, Spaan CN, Johannes de Boer R, Ramesh P, Martins Garcia T, Meijer BJ, et al. Driver mutations of the adenoma-carcinoma sequence govern the intestinal epithelial global translational capacity. Proc Natl Acad Sci USA. 2020;117:25560-70.

34. Rao X, Huang $X$, Zhou Z, Lin X. An improvement of the $2^{-\Delta \Delta C T}$ method for quantitative real-time polymerase chain reaction data analysis. Biostat Bioinforma Biomath. 2013;3:71-85.

35. de Jonge WJ, Hallemeesch MM, Kwikkers KL, Ruijter JM, de Gier-de Vries C, van Roon MA, et al. Overexpression of arginase $I$ in enterocytes of transgenic mice elicits a selective arginine deficiency and affects skin, muscle, and lymphoid development. Am J Clin Nutr. 2002;76:128-40.

36. van Eijk HM, Rooyakkers DR, Deutz NE. Rapid routine determination of amino acids in plasma by high-performance liquid chromatography with a 2-3 microns spherisorb ODS II column. J Chromatogr. 1993;620:143-8.

37. Mills PB, Struys E, Jakobs C, Plecko B, Baxter P, Baumgartner $M$, et al. Mutations in antiquitin in individuals with pyridoxine-dependent seizures. Nat Med. 2006;12:307-9.

38. Fearon ER, Vogelstein B. A genetic model for colorectal tumorigenesis. Cell. 1990;61:759-67.

39. Kurlishchuk Y, Vynnytska-Myronovska B, Grosse-Gehling P, Bobak Y, Manig F, Chen $\mathrm{O}$, et al. Co-application of canavanine and irradiation uncouples anticancer potential of arginine deprivation from citrulline availability. Oncotarget. 2016;7:73292-308.

40. Sabates-Bellver J, Van der Flier LG, de Palo M, Cattaneo E, Maake C, Rehrauer H, et al. Transcriptome profile of human colorectal adenomas. Mol Cancer Res. 2007;5:1263-75.

41. Sansom OJ, Reed KR, Hayes AJ, Ireland H, Brinkmann H, Newton IP, et al. Loss of Apc in vivo immediately perturbs Wnt signaling, differentiation, and migration. Genes Dev. 2004;18:1385-90.

42. Long Y, Tsai WB, Chang JT, Estecio M, Wangpaichitr M, Savaraj N, et al. Cisplatininduced synthetic lethality to arginine-starvation therapy by transcriptional suppression of ASS1 is regulated by DEC1, HIF-1alpha, and c-Myc transcription network and is independent of ASS1 promoter DNA methylation. Oncotarget. 2016;7:82658-70.

43. Crump NT, Hadjinicolaou AV, Xia M, Walsby-Tickle J, Gileadi U, Chen JL, et al. Chromatin accessibility governs the differential response of cancer and $T$ cells to arginine starvation. Cell Rep. 2021;35:109101.

44. Tsai WB, Long Y, Chang JT, Savaraj N, Feun LG, Jung M, et al. Chromatin remodeling system p300-HDAC2-Sin3A is involved in arginine starvation-induced HIF1a degradation at the ASS1 promoter for ASS1 derepression. Sci Rep. 2017;7:10814.

45. de Jonge WJ, Kwikkers KL, te Velde AA, van Deventer SJ, Nolte MA, Mebius RE, et al. Arginine deficiency affects early $B$ cell maturation and lymphoid organ development in transgenic mice. J Clin Invest. 2002;110:1539-48.

46. Alexandrou C, Al-Aqbi SS, Higgins JA, Boyle W, Karmokar A, Andreadi C, et al. Sensitivity of colorectal cancer to arginine deprivation therapy is shaped by differential expression of urea cycle enzymes. Sci Rep. 2018;8:12096.

\section{ACKNOWLEDGEMENTS}

We would like to thank Prof. Dr. W.H. Lamers for providing us with the Ass1 knockout mice.

\section{AUTHOR CONTRIBUTIONS}

J.H.M.vdM., R.dB., J.H., M.B., G.vdB., and V.M. conceptualized and designed the study. J.vdM., R.dB., B.M., W.S., J.V., S.M., M.vR., P.K., E.D., T.H., J.K., L.H., E.S., and V.M. acquired data. J.vdM., R.dB., B.M., W.S., T.H., J.K., L.H., J.H., E.S., M.B., G.vdB., and V.M. analyzed and interpreted the data. J.H.M.vdM., G.vdB., and V.M. drafted the article. All authors revised the article critically for important intellectual content and gave final approval of the version to be published.

\section{FUNDING}

This work was supported by grants from the Dutch Cancer Society (KWF/UVA 20136135 and KWF/Alpe 11053/2017-1).

\section{ETHICS APPROVAL AND CONSENT TO PARTICIPATE}

All patients provided written informed consent and patient material was used according to the guidelines of the Medical Ethical Committees of the Academic Medical Center and Leiden University Medical Center. All animal experiments were performed in accordance with the Animal Ethical Committee guidelines of the Academic Medical Center in Amsterdam. 


\section{COMPETING INTERESTS}

The authors declare no competing interests.

\section{ADDITIONAL INFORMATION}

Supplementary information The online version contains supplementary material available at https://doi.org/10.1038/s41419-021-04173-x.

Correspondence and requests for materials should be addressed to Vanesa Muncan.

Reprints and permission information is available at http://www.nature.com/reprints

Publisher's note Springer Nature remains neutral with regard to jurisdictional claims in published maps and institutional affiliations.
Open Access This article is licensed under a Creative Commons Attribution 4.0 International License, which permits use, sharing, adaptation, distribution and reproduction in any medium or format, as long as you give appropriate credit to the original author(s) and the source, provide a link to the Creative Commons license, and indicate if changes were made. The images or other third party material in this article are included in the article's Creative Commons license, unless indicated otherwise in a credit line to the material. If material is not included in the article's Creative Commons license and your intended use is not permitted by statutory regulation or exceeds the permitted use, you will need to obtain permission directly from the copyright holder. To view a copy of this license, visit http://creativecommons. org/licenses/by/4.0/.

(c) The Author(s) 2021 